\title{
Contribution of Genoarchitecture to Understanding Forebrain Evolution and Development, with Particular Emphasis on the Amygdala
}

\author{
Loreta Medina Munisamy Bupesh Antonio Abellán \\ Laboratory of Brain Development and Evolution, Department of Experimental Medicine, Faculty of Medicine, \\ University of Lleida, Institute of Biomedical Research of Lleida (IRBLLEIDA), Lleida, Spain
}

\section{Key Words}

Pallium • Subpallium • Hypothalamus • Pax6 - Islet1 •

$\mathrm{Nkx2.1} \cdot$ Otp $\cdot$ LIM-homeobox

\begin{abstract}
The amygdala is a forebrain center involved in functions and behaviors that are critical for survival (such as control of the neuroendocrine system and homeostasis, and reproduction and fear/escape responses) and in cognitive functions such as attention and emotional learning. In mammals, the amygdala is highly complex, with multiple subdivisions, neuronal subtypes, and connections, making it very difficult to understand its functional organization and evolutionary origin. Since evolution is the consequence of changes that occurred in development, herein we review developmental data based on genoarchitecture and fate mapping in mammals (in the mouse model) and other vertebrates in order to identify its basic components and embryonic origin in different species and understand how they changed in evolution. In all tetrapods studied, the amygdala includes at least 4 components: (1) a ventral pallial part, characterized by expression of Lhx2 and Lhx9, that includes part of the basal amygdalar complex in mammals and a caudal part of the dorsal ventricular ridge in sauropsids and also produces a cell subpopulation of the medial amygdala; (2) a striatal part, char-
\end{abstract}

acterized by expression of Pax6 and/or Islet1, which includes the central amygdala in different species; (3) a pallidal part, characterized by expression of Nkx2.1 and, in amniotes, Lhx6, which includes part of the medial amygdala, and (4) a hypothalamic part (derived from the supraoptoparaventricular domain or SPV), characterized by Otp and/or Lhx5 expression, which produces an important subpopulation of cells of the medial extended amygdala (medial amygdala and/or medial bed nucleus of the stria terminalis). Importantly, the size of the SPV domain increases upon reduction or lack of Nkx2.1 function in the hypothalamus. It appears that Nkx2.1 expression was downregulated in the alar hypothalamus during evolution to mammals, which may have produced an enlargement of SPV and the amygdalar cell subpopulation derived from it.

Copyright $\odot 2011$ S. Karger AG, Basel

\section{Introduction}

The brain in different vertebrates is organized according to a common plan (or Bauplan) and consists of the same major divisions and subdivisions in fishes, amphibians, sauropsids (including reptiles and birds), and mammals [reviews in Nieuwenhuys et al., 1998; Striedter, 2005; Kaas and Bullock, 2007]. However, brain divisions and

\section{KARGER}

Fax +41613061234 E-Mail karger@karger.ch www.karger.com (c) 2011 S. Karger AG, Basel

0006-8977/11/0783-0216\$38.00/0

Accessible online at:

www.karger.com/bbe
Loreta Medina, $\mathrm{PhD}$

Department of Experimental Medicine, Faculty of Medicine

University of Lleida, carrer Montserrat Roig 2

ES-25008 Lleida, Catalonia (Spain)

Tel. +34 973702 413, E-Mail loreta.medina@mex.udl.cat 


\begin{tabular}{|c|c|c|c|}
\hline \multicolumn{4}{|c|}{ Abbreviations used in this paper } \\
\hline \multirow[t]{2}{*}{$A 9 / A 10$} & A9 and A10 dopaminergic cell groups (substantia & ic & internal capsule \\
\hline & nigra and ventral tegmental area) & IHA & interstitial nucleus of the apical hyperpallium \\
\hline AAd & anterior amygdala, dorsal part & & (chicken) \\
\hline AAv & anterior amygdala, ventral part & IM & intercalated masses of the amygdala, main part \\
\hline $\mathrm{ac}$ & anterior commissure & ITC & intercalated cell groups of the amygdala \\
\hline ACo & anterior cortical amygdalar area & $\mathrm{L}$ & lateral amygdalar nucleus \\
\hline $\mathrm{AHi}$ & amygdalo-hippocampal area (chicken) & LA & lateral amygdala (ventral pallial amygdala in \\
\hline ANR & anterior neural ridge & & amphibians) \\
\hline $\mathrm{APH}$ & parahippocampal area (chicken) & LGE & lateral ganglionic eminence (striatal subdivision in \\
\hline \multirow[t]{2}{*}{ Arc } & arcopallium (part of the pallial amygdala in the & & mammals) \\
\hline & chicken) & LGEd & dorsal LGE \\
\hline ArA & arcopallium, anterior part & LGEv & ventral LGE \\
\hline Bas & basal nucleus (Meynert) & LP & lateral pallium \\
\hline $\mathrm{BC}$ & basal amygdalar complex & LSt & lateral striatum (chicken) \\
\hline $\mathrm{BL}$ & basolateral amygdalar nucleus & M & mesopallium (lateral pallium in chicken) \\
\hline $\mathrm{BLa}$ & anterior $\mathrm{BL}$ & $\mathrm{MB}$ & midbrain \\
\hline BLp & posterior $\mathrm{BL}$ & MDLP & pallial territory above the ventral pallium (including \\
\hline BLv & ventral BL & & medial, dorsal and lateral subdivisions, if present) \\
\hline $\mathrm{BM}$ & basomedial amygdalar nucleus & $\mathrm{Me}$ & medial amygdala (medial amygdalar nucleus) \\
\hline BST & bed nucleus of the stria terminalis & $\mathrm{MeA}$ & medial amygdala, anterior part (mouse) \\
\hline \multirow[t]{2}{*}{ BSTia } & bed nucleus of the stria terminalis, intra-amygdaloid & $\mathrm{MeA}$ & medial amygdala in nonmammals \\
\hline & part & MeAs & subpallial medial amygdala (chicken) \\
\hline BSTL & bed nucleus of the stria terminalis, lateral part & $\mathrm{MeP}$ & medial amygdala, posterior part (mouse) \\
\hline BSTLd & dorsal part of BSTL (chicken) & $\mathrm{MePD}$ & medial amygdala, posterodorsal part \\
\hline \multirow[t]{2}{*}{ BSTLdl } & lateral part of BSTLd (or dorsolateral BSTL) & MePV & medial amygdala, posteroventral part \\
\hline & (chicken) & MePVc & medial amygdala, posteroventral part, central \\
\hline \multirow[t]{2}{*}{ BSTLdm } & medial part of BSTLd (or dorsomedial BSTL) & & subdivision \\
\hline & (chicken) & MePVs & medial amygdala, posteroventral part, superficial \\
\hline BSTLv & ventral part of BSTL (chicken) & & subdivision \\
\hline BSTM & bed nucleus of the stria terminalis, medial part & MGE & medial ganglionic eminence (pallidal subdivision in \\
\hline BSTM1 & dorsolateral subnucleus of BSTM (chicken) & & mammals) \\
\hline BSTM2 & ventromedial subnucleus of BSTM (chicken) & MGEd & medial ganglionic eminence, dorsal part \\
\hline $\mathrm{cc}$ & corpus callosum & MGEvc & medial ganglionic eminence, ventrocaudal part \\
\hline CDL & dorsolateral corticoid area (chicken) & & (previously named or included as part of the anterior \\
\hline $\mathrm{Ce}$ & central amygdala (central amygdalar nucleus) & & peduncular area or AEP) \\
\hline CLSt & caudolateral part of striatum (chicken) & MP & medial pallium \\
\hline $\mathrm{CPu}$ & caudate-putamen & MSt & medial striatum (chicken) \\
\hline $\mathrm{DB}$ & nuclei of the diagonal band & $\mathrm{N}$ & nidopallium (part of the ventral pallium in chicken) \\
\hline DLP & caudal dorsolateral pallium (chicken) & NI & nidopallium intermedium (chicken) \\
\hline $\mathrm{DP}$ & dorsal pallium & NC & nidopallium caudale or caudal nidopallium (chicken) \\
\hline DVR & dorsal ventricular ridge & NCL & caudolateral nidopallium (chicken) \\
\hline EA & extended amygdala & $\mathrm{NCx}$ & neocortex \\
\hline EAce & central extended amygdala & ot & optic tract \\
\hline EAcel & lateral part of the central EA (chicken) & p1 & prosomere 1 \\
\hline EAcem & medial part of the central EA (chicken) & $\mathrm{p} 2$ & prosomere 2 \\
\hline EAme & medial extended amygdala & p3 & prosomere 3 \\
\hline ec & external capsule & $\mathrm{P}$ & pallium \\
\hline Emt & thalamic (or prethalamic) eminence & $\mathrm{Pa}$ & pallidum or pallidal subdivision (MGE in \\
\hline Ept & epithalamus & & nonmammals) \\
\hline GP & globus pallidus & $\mathrm{PA}$ & pallial amygdala \\
\hline $\mathrm{H}$ & hyperpallium (dorsal pallium derivative in chicken) & Pad & dorsal pallidal subdivision (chicken) \\
\hline $\mathrm{Ha}$ & alar hypothalamus & Pav & ventral pallidal subdivision (chicken) \\
\hline $\mathrm{HA}$ & apical hyperpallium (chicken) & PCo & posterior cortical amygdalar area \\
\hline $\mathrm{Hb}$ & basal hypothalamus & Pir & piriform cortex \\
\hline $\mathrm{HF}$ & hippocampal formation & PLCo & posterolateral cortical amygdalar area \\
\hline
\end{tabular}




\begin{tabular}{|c|c|}
\hline \multicolumn{2}{|c|}{ Abbreviations used in this paper } \\
\hline PMCo & posteromedial cortical amygdalar area \\
\hline $\mathrm{PO}$ & preoptic area \\
\hline POC & $\begin{array}{l}\text { commissural preoptic area (or commissural } \\
\text { septo-preoptic area) }\end{array}$ \\
\hline POB & basal or ventral preoptic area \\
\hline poh & preopto-hypothalamic boundary \\
\hline $\mathrm{Pt}$ & pretectum \\
\hline PTh & prethalamus \\
\hline PVN & paraventricular hypothalamic nucleus \\
\hline $\mathrm{rp}$ & roof plate \\
\hline $\mathrm{S}$ & subpallium \\
\hline $\mathrm{SCN}$ & suprachiasmatic domain \\
\hline $\mathrm{Se}$ & septum \\
\hline $\mathrm{SO}$ & supraoptic nucleus \\
\hline $\mathrm{Sp}$ & subpallium \\
\hline SPV & supraoptoparaventricular hypothalamic domain \\
\hline St & $\begin{array}{l}\text { striatum or striatal subdivision (LGE in non- } \\
\text { mammals) }\end{array}$ \\
\hline Std & dorsal striatal subdivision (chicken) \\
\hline Stv & ventral striatal subdivision (chicken) \\
\hline Th & thalamus \\
\hline vaf & $\begin{array}{l}\text { ventral amygalofugal tract (also known as occipito- } \\
\text { mesencephalic tract) }\end{array}$ \\
\hline ve & ventricle \\
\hline $\mathrm{VP}$ & ventral pallium \\
\hline
\end{tabular}

subdivisions show different relative sizes and complexities in different groups, and this is often correlated to differences in behavior and ecological adaptations of different vertebrate classes, orders, families, and/or species [Striedter, 2005]. The most rostral or anterior part of the brain, called the forebrain, shows the largest relative size and complexity in mammals and sauropsids and is considered responsible for the high cognitive abilities and the sophisticated and ample repertoire of behaviors that characterize these groups. During development, the forebrain is subdivided into the diencephalic vesicle (giving rise to the thalamus, pretectum, and other structures) and the secondary prosencephalon (giving rise to the hypothalamus, the optic vesicle, and the telencephalon) (fig. 1) [Puelles et al., 1987, 2004; Puelles, 2001a; Medina, 2008a]. Again, these different forebrain divisions and their subdivisions show important differences in mammals versus sauropsids as well as between species inside each group [Striedter, 2005]. For example, the collothalamus (receiving collicular sensory input) and its targets in the telencephalic pallium are quite large and elaborated in sauropsids, while the lemnothalamus (receiving lemniscal sensory input) and its targets in the pallium/cere-

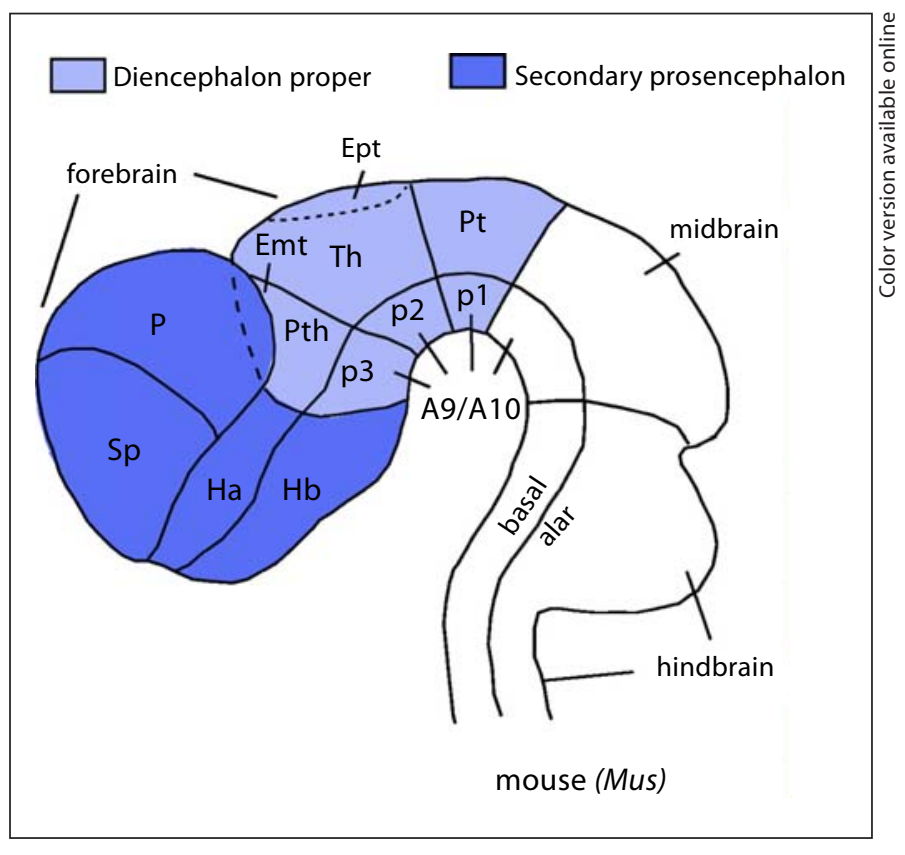

Fig. 1. Schematic diagram of a lateral view of the mouse embryonic brain representing the forebrain and its major divisions and subdivisions. Note that the forebrain shows two major transversal divisions named the diencephalon proper and the secondary prosencephalon (shown in different colors). The secondary prosencephalon produces the telencephalon dorsally (with the pallium and subpallium), the optic vesicle laterally (not represented), and the hypothalamus ventrally (the latter includes alar and basal parts). The amygdala originates in the secondary prosencephalon and includes pallial, subpallial, and alar hypothalamic cell groups. For abbreviations see list.

bral cortex show the largest size in mammals [Butler, 1994a, b; Medina and Reiner, 2000; Puelles, 2001b; Medina, 2007b; Medina and Abellán, 2009]. It appears that these brain differences were produced in evolution as a consequence of changes in developmental mechanisms [Carroll et al., 2001; Puelles and Medina, 2002; Medina, 2007a, 2008a; Striedter and Charvet, 2008; Charvet and Striedter, 2009a, b; Medina and Abellan, 2009]. This has led to the use of an evo-devo approach for understanding the developmental mechanisms that underlie the evolution of body and brain design. With this approach in mind, here we will review data on the development of the forebrain in different vertebrates, and we will try to identify common developmental patterns underlying conservation as well as aspects and possible mechanisms that may be responsible for evolutionary changes. Among the developmental data analyzed, we will pay especial attention to the genoarchitecture (term recently coined by Fer- 
ran et al. [2007, 2009]), i.e. combinatorial expression patterns of developmental regulatory genes within the topological framework of the neural tube that help to identify the same basic embryonic divisions or fields in the central nervous system of different vertebrates, which is useful for correlation and interpretation of other developmental data (such as fate mapping or the phenotype of a knockout animal for a specific gene) and for understanding the degree of conservation and variation of adult field-homologous structures [Puelles and Medina, 2002; Medina, 2007a]. It is important to emphasize that our genoarchitectonic analysis relies on the identification of domains with specific topological positions within the neural tube that are characterized by a specific molecular code (this is a combinatorial expression pattern of key regulatory genes, such as genes encoding transcription factors that play important roles in development). Therefore, using single genes or combinations of genes for identifying homologous structures disregarding the topological framework of the neural tube often leads to erroneous interpretations. We will focus on the amygdala, a telencephalic center involved in the control of emotions and social behavior that has been found at least in all tetrapods [reviews by Moreno and González, 2006; Martínez-García et al., 2007]; its development has been investigated in depth using genetic and fate map tools in recent years [Puelles et al., 2000; Medina et al., 2004; Remedios et al., 2004, 2007; Tole et al., 2005; Moreno and González, 2007a, b; Abellán and Medina, 2008, 2009; García-López et al., 2008; Moreno et al., 2008a, b, 2009; Abellán et al., 2009, 2010; Hirata et al., 2009; Soma et al., 2009; GarcíaMoreno et al., 2010; Waclaw et al., 2010; Bupesh et al., 2011a, b]. Since the amygdala in different tetrapods also appears to include neurons derived from extratelencephalic domains [Bardet et al., 2008; Abellán et al., 2010; García-Moreno et al., 2010], we will start with a brief summary of some aspects of forebrain development that help to understand its basic divisions and organization.

\section{Basic Organization and Development of the Forebrain}

As noted above, the forebrain is transversally subdivided during development into the diencephalic vesicle (or diencephalon proper) caudally and the secondary prosencephalon rostrally (fig. 1). Like other parts of the neural tube, the forebrain and its major transversal subdivisions are further subdivided into at least 4 main longitudinal zones which from dorsal to ventral are named roof, alar, basal, and floor plates [Puelles and Rubenstein, 1993, 2003; Puelles, 2001a; Puelles et al., 2004, 2007]. This results in a neural tube with multiple subdivisions along the rostrocaudal and dorsoventral axis, each being characterized by: (1) a specific location in the bidimensional coordinate diagram (topological framework) of the tube, (2) expression of a specific combination of developmental regulatory genes, and (3) production of specific cell groups (refer to publications cited above for details). In each hemisphere, the secondary prosencephalon produces the hypothalamus ventrally, the optic vesicle laterally, and the telencephalon dorsally. The diencephalon produces the pretectum, epithalamus, thalamus, prethalamus, and thalamic (or prethalamic) eminence dorsally, and several prerubral and retromammillary areas ventrally, including the diencephalic parts of the A9 and A10 dopaminergic cell groups (fig. 1) [Puelles et al., 1987, 2004, 2007; García-López et al., 2004; Ferran et al., 2007, 2009; Smidt and Burbach, 2007; Medina, 2008a, b]. Abundant developmental data on chemo- and genoarchitecture and fate mapping support this general scheme in different vertebrates, including fishes [Murakami et al., 2001; Wullimann and Mueller, 2004; Osorio et al., 2005; Mueller et al., 2006, 2008; Mueller and Wullimann, 2009; Pombal et al., 2009; Martinez-de-la-Torre et al., 2010], amphibians [Bachy et al., 2001, 2002; Brox et al., 2003, 2004; Moreno et al., 2004, 2008a, b; van den Akker et al., 2008], sauropsids [Puelles et al., 1987, 2000, 2004; Cobos et al., 2001; García-López et al., 2004], and mammals [Puelles and Rubenstein, 1993; Shimamura et al., 1995, 1997; Shimamura and Rubenstein, 1997; Rubenstein et al., 1998; Puelles et al., 2000, 2004]. For example, in all vertebrates studied thus far, from jawless fishes to mammals, the alar forebrain region expresses the transcription factor Pax6 during development while the basal plate expresses Nk2 family transcription factors, such as Nkx2.1 and Nkx2.2 [Stoykova and Gruss, 1994; Fernandez et al., 1998; Sussel et al., 1999; Puelles et al., 2000; Murakami et al., 2001; Bachy et al., 2002; Moreno et al., 2008b; van den Akker et al., 2008]. These and other regulatory genes such as Sonic hedgehog help to distinguish the alar-basal boundary and the longitudinal axis, which is markedly or strongly bended, particularly in sauropsids and mammals, due to the extraordinary growth of the alar regions. It is important to remark that the regulatory genes on which the forebrain organization proposal rests have been shown to play key roles in different aspects of development that include patterning and specification of different progenitor zones, neurogenesis, and cellular differentiation [e.g. reviews by Wilson and $\mathrm{Ru}-$ 
benstein, 2000; Wilson and Houart, 2004; Lupo et al., 2006]. However, except in a few instances, we will not explain the functions of these genes since it is beyond the aim of this article.

The forebrain and its major subdivisions have already been evidenced at neural plate stages by gene expression patterns and fate mapping studies [Rubenstein et al., 1998; Wilson and Rubenstein, 2000; Cobos et al., 2001; Puelles et al., 2004; Sánchez-Arrones et al., 2009]. Molecular signals from the anterior neural ridge (ANR; a secondary organizer located at the anterior end of the plate) are very important for the rostrocaudal parcellation of the forebrain and for later developmental events [Wilson and Houart, 2004; Medina, 2008a; Medina and Abellán, 2009]. The earliest ANR signals include antagonists of Wnt proteins (secreted Frizzled-related proteins) such as Tlc, which are opposed to Wnt proteins produced in the caudal forebrain [Wilson and Houart, 2004]. Wnt proteins caudalize the forebrain (forming the diencephalon proper, sometimes referred to as the caudal diencephalon), whereas Wnt antagonists produced at the ANR are important for the formation of the rostral forebrain, including the telencephalon, eye field, and hypothalamus. Zebrafish embryos that carry a mutation affecting the intracellular Wnt pathway (Masterblind mutants) show loss of telencephalon and eyes, and expansion of the diencephalon proper to the front of the neural plate. Studies in frogs (the anuran Xenopus), chicks, and mice also support that Wnt signals promote posterior forebrain fates (diencephalon proper) but suppress anterior forebrain fates [Wilson and Houart, 2004]. Under the influence of ANR signals, the rostral forebrain shows low Wnt activity and, in this condition, starts to express the transcription factor Sine-oculis (Six; in particular Six 3 and related proteins), which is extremely important for rostral forebrain formation [Wilson and Houart, 2004]. Removal of the ANR (the source of Wnt antagonists) or enhanced Wnt activity suppresses Six 3 expression in the anterior neural plate, producing the effects mentioned above. Moreover, absence of Six 3 (as occurs in knockout mice) produces agenesis of the secondary prosencephalon, including the telencephalon, eye field, and hypothalamus, while the diencephalon proper is expanded rostrally [Lagutin et al., 2003]. Together, all of these data clearly support that the diencephalon proper and the secondary prosencephalon constitute two distinct transversal subdivisions of the forebrain and that the hypothalamus, classically considered part of the diencephalon together with the thalamus, develops in a separate domain rostral to the latter (fig. 1).
As explained below in more detail, the amygdala develops in the alar plate of the secondary prosencephalon and includes at least telencephalic and hypothalamic neurons. It was first described as an almond-shape structure in the temporal lobe of the cerebral hemispheres in humans, and a corresponding structure was later found in the caudolateral telencephalon of other mammals, such as rodents [Swanson and Petrovich, 1998]. However, its location and extension in sauropsids has remained highly controversial [reviewed in Striedter, 1997; Puelles, 2001b; Jarvis et al., 2005; Martínez-García et al., 2007; Medina and Abellán, 2009]. A large amount of developmental data published in recent years has provided highly interesting information on the embryonic and molecular identity of amygdalar components in mammals [Puelles et al., 2000; Medina et al., 2004; Remedios et al., 2004; Tole et al., 2005; Hirata et al., 2009; Soma et al., 2009; García-Moreno et al., 2010; Waclaw et al., 2010; Bupesh et al., 2011a, b]. Little by little, similar information is being collected in other vertebrates, and these data are becoming essential for understanding the development and evolution of this structure. These data will be reviewed in the following sections.

\section{Development and Evolution of the Amygdala}

\section{The Amygdala in Mammals: Pallial versus Subpallial Parts}

Almost a century ago, the Swedish embryologist Nils Holmgren proposed that the mammalian amygdala consists of pallial and subpallial parts which represent the caudal poles of the two major embryonic divisions of the telencephalon [Holmgren, 1925]. This initial proposal has been confirmed by recent developmental data, mostly in the mouse, that include differential expression of transcription factors and other regulatory proteins that distinguish the pallium from the subpallium (fig. 2) [Puelles et al., 2000; Medina et al., 2004; García-López et al., 2008] and genetic and experimental fate maps of pallial or subpallial progenitor domains [Hirata et al., 2009; Soma et al., 2009; Waclaw et al., 2010; Bupesh et al., 2011a, b]. This proposal also agrees with and provides and explanation for the differences found in neurochemistry and connections of pallial versus subpallial parts of the amygdala, which showed that pallial parts are similar to the cerebral cortex, while subpallial parts resemble the basal ganglia [Alheid and Heimer, 1988; Swanson and Petrovich, 1998]. Some of these differences are explained in more detail below. 

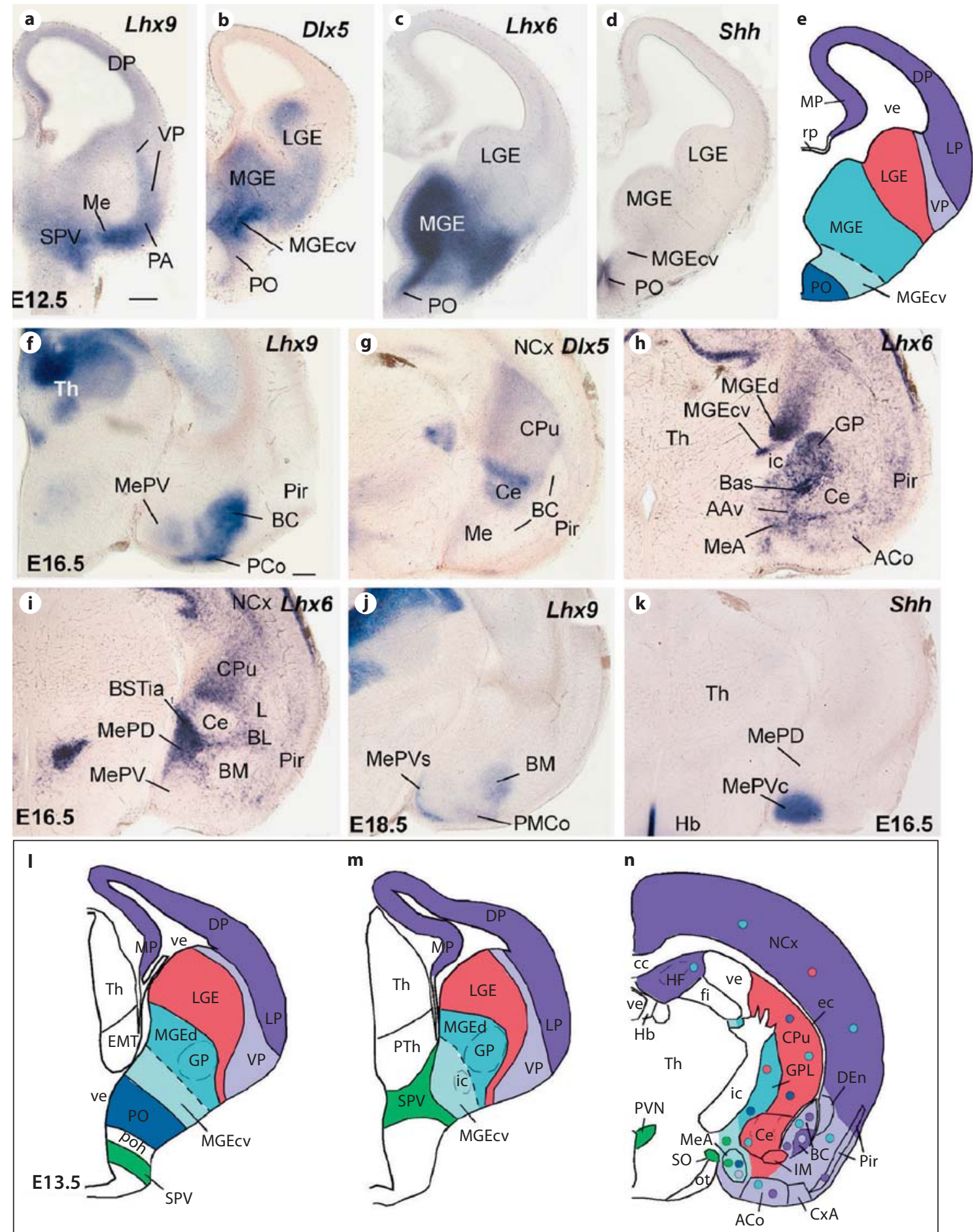

Fig. 2. Frontal sections through the telencephalon of mouse embryos showing the mRNA expression of different developmental regulatory genes, as indicated on each panel, at E12.5 (a-d), E16.5 $(\mathbf{f}-\mathbf{i}, \mathbf{k})$, or E18.5 (j). e, I, m Schematic drawings of frontal sections of the mouse embryonic telencephalon and hypothalamus at E12.5 (e) or E13.5 (I, m) showing the major divisions and subdivisions in different colors. $\mathbf{n}$ Drawing of a frontal section through the adult mouse forebrain at the level of the anterior amygdala showing the derivatives of each embryonic domain in different colors (for more details on derivatives at caudal amygdalar levels, refer to the text and to publications by Medina et al. [2004], García-López et al. [2008], and Bupesh et al. [2011a]). The colored circles represent immigrant neurons. Scale bars $=200 \mu \mathrm{m}(\mathbf{a}-\mathbf{k})$. For abbreviations see list. 
Pallial Amygdala in Mammals

Based on the combinatorial expression of the mRNA of transcription factors and other regulatory proteins typical of the pallium, such as Neurogenin 2, Emx1, and Tbrl, the basal amygdalar complex and the cortical amygdalar areas were proposed to derive from ventral and lateral pallial sectors [Puelles et al., 2000; Medina et al., 2004], and this has been shown by genetic and experimental fate maps [Gorski et al., 2002; Hirata et al., 2009; Soma et al., 2009; Waclaw et al., 2010; Bupesh et al., 2011a]. Neurogenin 1/2 [Wullimann and Mueller, 2004; Osorio et al., 2010] and Tbr1 [Hevner et al., 2001] appear to be involved in the generation or differentiation, respectively, of glutamatergic cells, which explains why most neurons in the basal amygdalar complex and cortical amygdalar areas, like those in other parts of the pallium, are glutamatergic and show excitatory projections [McDonald, 1996; Swanson and Petrovich, 1998; Medina and Abellán, 2009]. In particular, the ventral pallium - characterized by distinct expression of Dbx1 (in addition to Pax6 and Lhx2) but a lack of Emxl in the ventricular zone, and by expression of Tbrl, Ngn2, Lhx2, Lhx9, and semaphorin 5A in the mantle (fig. 2) - was proposed to be a major source of neurons for part of the basal amygdalar complex (including at least the lateral and basomedial nuclei), the anterior and posteromedial cortical amygdalar areas, and layer 1 of the nucleus of the lateral olfactory tract [Puelles et al., 2000; Medina et al., 2004; Tole et al., 2005; García-López et al., 2008; Abellán et al., 2009] (fig. 3). Most of this proposal has recently been shown by genetic and experimental fate maps [Hirata et al., 2009; Waclaw et al., 2010; Bupesh et al., 2011a]. However, data from a Dbx1 lineage fate map [Waclaw et al., 2010] suggest that part of the basolateral nucleus (perhaps its anterior subdivision or at least many of its cells) of the basal amygdalar complex may also derive from the ventral pallium (fig. 3).

Interestingly, data on expression of Tbrl and Lhx9 and recent experimental fate mapping indicate that the ventral pallium also produces some cells for the medial amygdala (fig. 2) [García-López et al., 2008; Bupesh et al., 2011a], a nucleus typically considered part of the subpallial amygdala based on neurochemistry, connections, and developmental data (see next section). It is likely that pallial-derived neurons of the medial amygdala are glutamatergic. These and other data explained below provide a new view of the medial amygdala as a mosaic-like structure with neurons of multiple embryonic origins [GarcíaLópez et al., 2008; Bupesh et al., 2011a] which need to be considered when comparing with other vertebrates for analysis of amygdalar evolution.
On the other hand, the lateral pallium is characterized by expression of Emx1, Pax6, and Lhx 2 in the ventricular zone, and Emx1, Tbrl, and Cadherin 8 in the mantle; based on this pattern it was proposed that the basolateral amygdalar nucleus and the posterolateral cortical amygdalar area may derive from this lateral pallial sector $[\mathrm{Pu}-$ elles et al., 2000; Medina et al., 2004]. As noted above, recent data from a Dbx1 lineage fate map [Waclaw et al., 2010] suggest that the anterior part of the basolateral nucleus may derive from the ventral pallium, leaving only the posterior and ventral subdivisions of this nuclear complex as putative lateral pallial derivatives (fig. 3). In addition, genetic fate mapping and other data indicate that a subpopulation of neurons within the ventral pallial amygdala or adjacent amygdalar areas (such as the nucleus of the lateral olfactory tract) appear to originate from Emx1-lineage pallial progenitors, perhaps from the lateral pallium [Puelles et al., 2000; Gorski et al., 2002; Medina et al., 2004] or the dorsal pallium [Remedios et al., 2007].

Moreover, the pallial amygdala (basal amygdalar complex and cortical amygdalar areas) also contains minor subpopulations of GABAergic interneurons, cocontaining different calcium-binding proteins or neuropeptides [Berdel and Morys, 2000; Kemppainen and Pitkänen, 2000; McDonald and Mascagni, 2001; Muller et al., 2003; Legaz et al., 2005], which originate in the subpallium [Legaz, 2006; Bupesh et al., 2011a]. However, it is important to note that not all calcium-binding protein-containing neurons of the pallial amygdala are GABAergic interneurons. For example, there is a minor subpopulation of calbindin neurons in the pallial amygdala that do not contain GABA [Kemppainen and Pitkänen, 2000] and originate in the pallium [Bupesh et al., 2011a].

\section{Subpallial Amygdala in Mammals}

Based on gene expression patterns, genetic fate maps, and migration assays, it has been proposed that the subpallial amygdala in mammals includes the central and intercalated amygdalar nuclei, the anterior amygdala, and a large part of the medial amygdala (fig. 2) [Puelles et al., 2000; Medina et al., 2004; García-López et al., 2008; Hirata et al., 2009; Soma et al., 2009; Waclaw et al., 2010; Bupesh et al., 2011a]. Most neurons in the subpallium, including those of the subpallial amygdala, and their projections are GABAergic [Swanson and Petrovich, 1998], and this is explained by the expression in this domain during the development of regulatory genes involved in the generation and differentiation of GABAergic neurons, such as Mash1 and Dlx1/2/5 [Anderson et al., 1999; 
Stühmer et al., 2002a, b; Wullimann and Mueller, 2004; Cobos et al., 2005a, b; Long et al., 2009; Osorio et al., 2010]. Recent data indicate that the 3 major subdivisions of the subpallium, i.e. striatal, pallidal, and preoptic, contribute neurons to the amygdala [García-López et al., 2008; Hirata et al., 2009; Waclaw et al., 2010; Bupesh et al., 2011a].

Striatal Amygdala. The striatal subdivision (lateral ganglionic eminence; LGE) is characterized by ventricular/subventricular zone expression of Dlx $1 / 2$ but a lack of Nkx2.1, and by expression of Dlx 5 in the subventricular zone and mantle (fig. 2). Based on these features, the central amygdalar nucleus, the intercalated nuclei, and the dorsal part of the anterior amygdala appear to represent LGE derivatives [Medina et al., 2004; García-López et al., 2008]. In the mouse, the LGE appears to show a dorsal subdivision characterized by production of postmitotic cells expressing Pax6, and a ventral subdivision characterized by expression of Islet1 in the subventricular zone and mantle [Puelles et al., 2000; Stenman et al., 2003; Flames et al., 2007]. Based on the expression of Pax6 and fate mapping, it appears that many neurons of the central amygdala originate in the dorsal LGE [Puelles et al., 2000; Bupesh et al., 2011b], and this appears to be true for the intercalated cells as well [Kaoru et al., 2010]. On the other hand, based on a genetic fate map of Islet1, many neurons of the central amygdala also originate in the ventral LGE [Waclaw et al., 2010; Bupesh et al., 2011b]. Central and intercalated nuclei of the amygdala are involved in the control of ingestion and fear responses by way of projections to specific nuclei of the hypothalamus and brainstem [Swanson, 2000; Paré et al., 2004]. However, it is unclear what specific role each distinct cell group of the central/intercalated amygdala may play.

Pallidal Amygdala. The pallidal subdivision (medial ganglionic eminence; MGE) shows ventricular and/or subventricular zone expression of the transcription factors Nkx2.1 and Lhx6, but its ventricular zone does not express the regulatory protein Sonic hedgehog (Shh); it also shows expression of Lhx6 in the mantle (fig. 2) [Flames et al., 2007; García-López et al., 2008]. Based on expression profiles and data from migration assays, the ventrocaudal MGE subdivision (MGEvc, previously named or included as part of the anterior peduncular area; fig. 2) appears to be the major source for the neurons of the posterodorsal medial amygdala and many neurons of the anterior medial amygdala [García-López et al., 2008; Bupesh et al., 2011a]. The Lhx6-expressing neurons of the medial amygdala receive olfactory input (from main and/or accessory olfactory bulbs) and appear

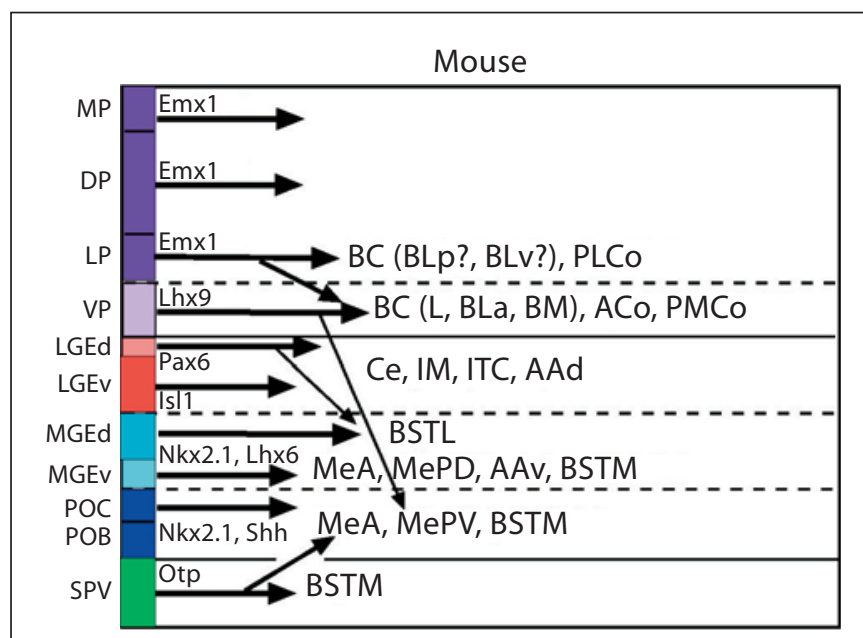

Chicken
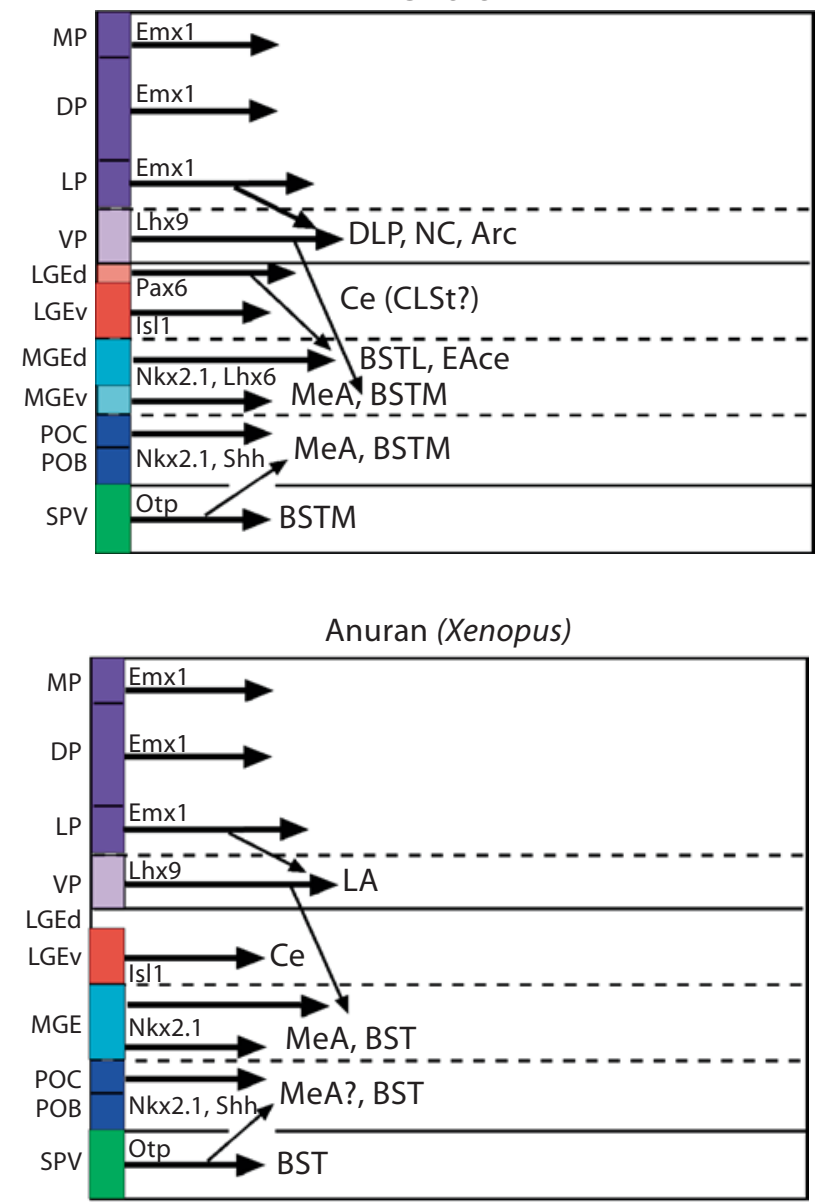

Fig. 3. Diagram representing the major embryonic divisions and subdivisions of the forebrain that produce neurons for the amygdala (arrows) in the mouse, the chicken, and the anuran Xenopus. Some of the developmental regulatory genes that characterize the divisions and subdivisions are also included. See text for more details. For abbreviations see list. 
to play a role in reproduction control by way of direct and indirect projections to hypothalamic centers involved in reproduction [Choi et al., 2005; García-López et al., 2008].

Preoptic Amygdala. The preoptic subdivision of the subpallium is characterized by ventricular expression of both Nkx2.1 and Shh (fig. 2) [Flames et al., 2007; GarcíaLópez et al., 2008] but also shows expression of other transcription factors such as Dbx1 [Hirata et al., 2009]. Based on gene expression profiles, migration assays, and genetic fate maps, the preoptic area has been shown to produce cells for the medial amygdala [García-López et al., 2008; Hirata et al., 2009; Carney et al., 2010; Bupesh et al., 2011a]. It appears that the neurons originate specifically in the commissural preoptic subdivision [Bupesh et al., 2011a] and that neurons reach primarily the anterior and posteroventral amygdala, where Shh-expressing and Dbx1-lineage cells are principally found (fig. 2) [for Shh see García-López et al., 2008; for Dbx1 see fig. 6 in Hirata et al., 2009, and fig. 1 in Waclaw et al., 2010]. According to the data from Hirata et al. [2009], many of the Dbx1 lineage neurons of the medial amygdala contain nitric oxide synthase (NOS) and may represent projection neurons [see discussion in Bupesh et al., 2011a]. The posteroventral part of the medial amygdala has been involved in defense control [Swanson, 2000]. However, since the posteroventral and particularly the anterior part of the medial amygdala contain cells from several origins, it would be important to know the specific connections of each particular neuron subtype.

The Medial Amygdala of Mammals Also Contains a Subpopulation of Extratelencephalic Neurons

Based on expression of the transcription factors Otp and Lhx5, the medial amygdala of the mouse was proposed to include an important neuron subpopulation derived from the supraoptoparaventricular domain of the alar hypothalamus (SPV) (fig. 2) [Bardet et al., 2008; Abellán et al., 2010; see also previous proposal of Puelles and Rubenstein, 2003, and discussion in García-López et al., 2008]. This domain produces the paraventricular and supraoptic hypothalamic nuclei, which are the major sources of the hypothalamo-hypophysial axis, and Otp and Sim 1 have been found to be essential for the development of these centers [Michaud et al., 1998; Wang and Lufkin, 2000]. Based on analysis of cells expressing Otp and Lhx5 during development, some cells produced in the SPV appear to extend tangentially into the telencephalon to invade the medial amygdala and other parts of the medial extended amygdala [Bardet et al., 2008; Abellán et al., 2010]. This has been confirmed recently by experimental fate maps [García-Moreno et al., 2010; Bupesh et al., 2011a] and analysis of Otp-knockout mice in which SPV-derived cells appeared to decline in the medial amygdala and medial bed nucleus of the stria terminalis (BST) [Wang and Lufkin, 2000; García-Moreno et al., 2010]. Based on correlation with vesicular glutamate transporter 2 (a marker of glutamatergic cells), it seems likely that SPV-derived cells of the medial amygdala are glutamatergic and their projections excitatory [Abellán et al., 2010; García-Moreno et al., 2010]. However, the connections and function of this specific subset of medial amygdalar neurons are unknown. Since the SPV appears to produce vasopressin (AVP) and oxytocin (OT) containing neurons of the paraventricular hypothalamic nucleus [Michaud et al., 1998; Wang and Lufkin, 2000], it is possible that AVP- and/or OT-expressing cells of the medial extended amygdala (including the medial BST and medial amygdala) also derive from SPV. These neurons of the medial extended amygdala have been involved in several aspects of social behavior [Cushing and Kramer, 2005]. Interestingly, neurons of this system are responsive to gonadal steroids and appear related to sex differences in some social behaviors and functions [de Vries and Miller, 1998].

Understanding the Amygdalar Mosaic in Mammals

As noted above, the amygdala of mammals is a highly complex and mosaic-like structure in terms of neuronal subtypes, molecular and neurochemical profiles, and connections [Alheid and Heimer, 1988; Swanson and Petrovich, 1998; Remedios et al., 2004]. The reason for this complexity is beginning to be elucidated thanks to developmental studies which have shown that the amygdala contains neurons that originate in multiple progenitor sectors, including at least 2 pallial, 3 subpallial, and 1 hypothalamic embryonic domain (fig. 2). It is also possible that some cells of the extended amygdala originate in the thalamic eminence [Puelles et al., 2000; Abellán et al., 2010], but this requires further investigation. The developmental regulatory genes expressed by each specific set of progenitor cells, the downstream genes expressed by the descendant cells during development, and the molecular environmental signals found during migration condition the differentiation and final fate of each set of amygdalar neurons. All of these factors need to be taken into consideration when comparing with other vertebrates and trying to understand amygdalar evolution. 
The Amygdala in Sauropsids and Amphibians and Some Conclusions on the Evolution of the Amygdala in Tetrapods

The first question we need to consider is whether the same embryonic domains (progenitor zones) that produce the amygdala in mammals are present in other tetrapods, including sauropsids and amphibians. The answer to this question is yes, at least for the major domains, but next we would need to consider the existence of the comparable subdomains. The next question to analyze is whether all of these major domains/subdomains in nonmammalian tetrapods produce amygdalarlike neurons comparable to those of mammals. We would also need to consider whether the same set of developmental regulatory genes that are involved in regional/ progenitor specification, neurogenesis, migration, and differentiation of amygdalar neurons that are found in mammals are also found in other vertebrates. The answers to these questions are not simple and will be discussed in the following paragraphs, considering pallial, subpallial, and hypothalamic parts separately. However, we must say that all of our conclusions are still tentative since detailed developmental data relevant to the amygdala are only available for extremely few species of tetrapods, the mouse Mus musculus, the chicken Gallus gallus domesticus, the turtles Emys orbicularis and Pseudemys scripta, the anuran Xenopus laevis, and the urodele Pleurodeles waltl (but turtle and urodele data are still quite scarce).

Pallial Amygdala in Sauropsids and Amphibians

In spite of the different morphological aspect in adults, the embryonic telencephalon of sauropsids and amphibians exhibits the same two major divisions that are present in that of mammals, i.e. pallium and subpallium, and this is considered to be the ancestral condition in tetrapods [reviewed by Striedter, 1997]. The existence of these two major divisions in the telencephalon of nonmammalian tetrapods is supported by fate mapping studies in chickens [Striedter et al., 1998; Cobos et al., 2001; Pombero and Martinez, 2009] and by their distinct gene expression patterns during development and inferred cellular derivatives (fig. 3-5; see next section). Data on expression of transcription factors and other regulatory proteins (or their mRNA) during development indicate that the pallium and subpallium are also characterized by the same basic combinatorial molecular codes in sauropsids, amphibians, and mammals. As in mammals, the ventricular zone of the pallium in chickens, turtles, and the anuran Xenopus expresses during development Pax6, Emx1, and
Lhx2, but not Dlx/Distal-less transcription factors, while the pallial mantle is characterized by Emx1, Tbrl, and Tbr2 (Eomes) (fig. 3-5) [Fernandez et al., 1998; Bulfone et al., 1999; Puelles et al., 2000; Bachy et al., 2002; Brox et al., 2004; Moreno et al., 2004, 2010; Abellán et al., 2009]. The pallium in Xenopus also expresses Neurogenin-related genes [Wullimann et al., 2005], but no data exists in avian or reptilian brains. The pallium in nonmammalian tetrapods is enriched with neurons expressing glutamaterelated markers [Fowler et al., 1999; Abellán et al., 2009; Medina and Abellán, 2009], suggesting that Tbrl and Ngn1/2 may play a similar role in the differentiation of these neurons in the pallium of all tetrapods.

At least 4 pallial subdivisions are present in the tetrapod species studied, and in all of them there is a ventral pallial sector characterized by a lack of ventricular expression of Emxl, and strong expression of Tbrl and Tbr2, but in general only few Emx1-expressing cells in the mantle (fig. 3-5) [Fernandez et al., 1998; Puelles et al., 2000; Brox et al., 2004; Abellán et al., 2009]. Importantly, these data support that the sauropsidian dorsal ventricular ridge (DVR; which includes the nidopallium, mesopallium, and arcopallium in birds [Reiner et al., 2004]), considered by some authors to contain cell groups comparable to specific cells of the lateral neocortex based on the general topographic position and similarity of connections [Karten, 1997; Jarvis et al., 2005; Butler et al., 2011], derives from the lateral and ventral pallial sectors, which means that the DVR cannot be considered comparable to any part of the neocortex since the latter is a derivative of the dorsal pallium [Puelles et al., 2000, 2007; Puelles, 2001b, 2011; Abellán et al., 2009]. The conclusion that the sauropsidian DVR derives from the lateroventral pallium while the mammalian neocortex derives from the dorsal pallium (implying that they are not homologous) is also supported by topological analysis that considers the internal coordinates of the neural tube and the relative position of radial domains; these remain invariant throughout development and across species sharing the same Bauplan [Striedter, 1997, 2005; Puelles, 2001a, b, 2011; Puelles and Medina, 2002; Medina, 2007a, b; Puelles et al., 2007; Medina and Abellán, 2009].

In initial studies based on genoarchitecture (with emphasis on the presence or relative abundance of Emx1expressing cells), it was proposed that lateral and ventral pallial sectors of sauropsids and amphibians contain caudal extensions that may include amygdalar derivatives [Puelles et al., 2000; Brox et al., 2004]. However, more recent analysis based on combinatorial expression of genes that distinguish the lateral pallium (such as FoxP1 

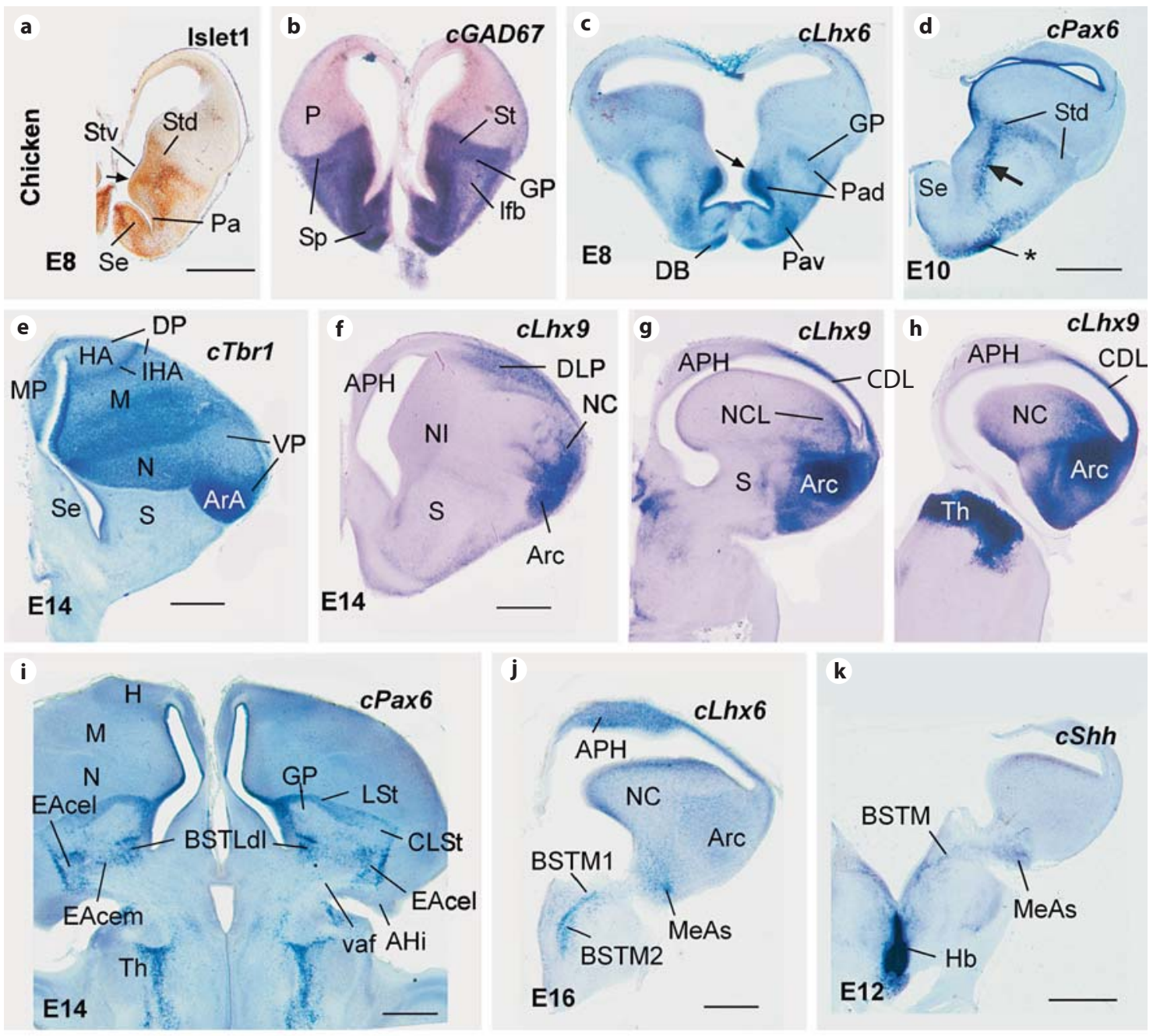

j

k
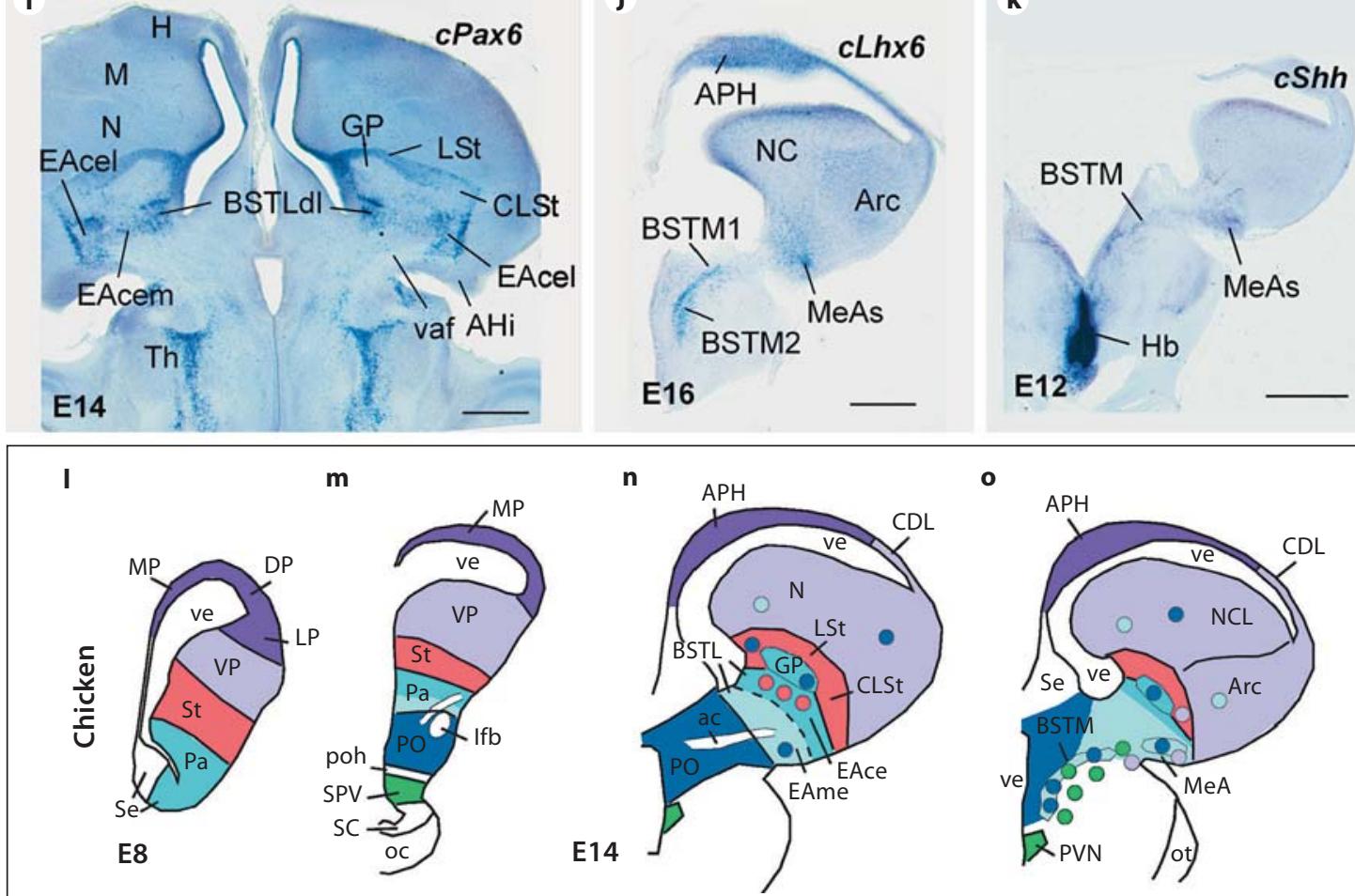

E14
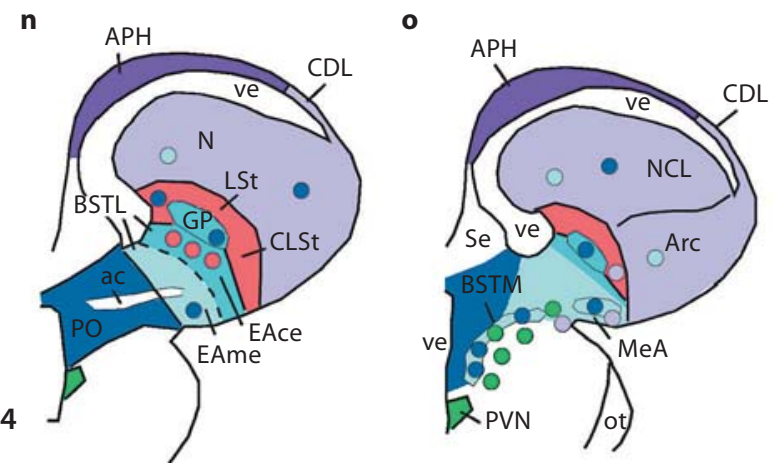

Fig. 4. Frontal (a-h) or oblique (i-k) sections through the telencephalon of chicken embryos showing the expression of different developmental regulatory genes (indicated on each panel) at E8 (a-c), E10 (d), E12 (k), E14 (e-i), or E16 (j). a Protein expression (immunohistochemistry). b-k mRNA expression (in situ hybridization). I-o Schematic drawings of frontal sections through the embryonic chicken telencephalon and hypothalamus showing the major embryonic divisions at E8 and the de- rivatives at E14 (in different colors). The arrows in $\mathbf{a}$ and $\mathbf{c}$ indicate the striato-pallidal boundary. The arrow in $\mathbf{d}$ points to a stream of Pax6-expressing cells that migrate from the dorsal striatal subdivision (Std) into the pallidal domain. The asterisk in d points to superficial cells expressing Pax6, part of which may come from the thalamic eminence [refer to Abellán and Medina, 2009, for details]. Scale bars $=1 \mathrm{~mm}(\mathbf{a}-\mathbf{d}, \mathbf{f}-\mathbf{k})$ and 400 $\mathrm{mm}(\mathbf{e})$. For abbreviations see list. 
[Teramitsu et al., 2004; Sandoval, 2011]) from the ventral pallium (such as Dachsund-2 [Szele et al., 2002; Puelles et al., 2007; Sandoval, 2011], and Lhx2 and Lhx9 [Abellán et al., 2009]), in combination with morphological landmarks and topology, suggest that the lateral pallium of sauropsids is smaller than previously thought and does not reach caudal aspects of the DVR. It appears that Dachsund-2 is strongly expressed in most of the ventral pallium (including the frontal, intermediate, and caudal nidopallium [Puelles et al., 2007; Sandoval, 2011]), while Lhx2 and Lhx9 are expressed in the caudal part of the ventral pallium (including the caudal nidopallium and arcopallium plus some superficial olfactorecipient areas [Abellán et al., 2009]; fig. 3, 4). Interestingly, the caudal aspect of the ventral pallium of the frog Xenopus is also characterized by expression in the mantle of the transcription factors Lhx2 and Lhx9 [Moreno et al., 2004]. Therefore, this is a common feature in mice, chickens, and Xenopus (fig. 3, 4) [Moreno et al., 2004; Tole et al., 2005; García-López et al., 2008; Abellán et al., 2009]. More importantly, in these different tetrapods, the caudal part of the ventral pallium expressing Lhx2 and Lhx9 is specifically related to the ventral pallial amygdala [Moreno et al., 2004; Tole et al., 2005; García-López et al., 2008; Abellán et al., 2009] (fig. 3, 4). In general, in the species studied the ventral pallial amygdalar area receives olfactory and thalamic (primarily multimodal) input, is reciprocally connected with other parts of the pallium, projects to the subpallium (including the septum, striatum, and subpallial amygdala) and hypothalamus, and is considered an associative center that modulates reward responses, attention, and associative learning of emotionally relevant events [for reviews see Moreno and González, 2006; Martínez-García et al., 2007; Medina and Abellán, 2009]. However, although this general ventral pallial amygdalar area of different tetrapods (including a large part of the basal complex and cortical areas of the amygdala in mammals and the caudal part of the DVR and some superficial olfactory areas in sauropsids) can be considered homologous as a field, we should not try to find one-to-one correspondences of specific nuclei or areas. Obviously, the ventral pallial amygdalar area was likely small in the last common ancestor of tetrapods, perhaps resembling that observed in modern amphibians, but this general area has become quite large and complex in mammals and sauropsids, showing distinct group- and species-specific specializations. An example is the exquisite control of vocalization by the ventral pallial amygdala that is present in songbirds and budgerigars [reviews by Martínez-García et al., 2007; Abellán et al., 2009].

Amygdalar Evolution and Development
Regarding a lateral pallial contribution to the amygdala comparable to that described in mammals, although it was once proposed to also exist in nonmammalian tetrapods based on high expression of Emx1 [Puelles et al., 2000; Brox et al., 2004; reviewed in Martínez-García et al., 2007], current knowledge suggests that a similar contribution may not be present in amphibians [Moreno and González, 2006] or possibly in chickens or other sauropsids [Abellán et al., 2009] (see previous paragraph for details) (fig. 3). Nevertheless, there is still some controversy regarding the origin of a dorsocaudal part of the pallium of the chicken, considered by Puelles et al. [2007] to be a caudal part of the lateral pallium; they called this region the caudal dorsolateral area (CDL). In support of this, the CDL shows high expression of Emx1 during development, as seen in fig. 10n of Puelles et al. [2000]. However, this area is proposed by us to represent a separate subdomain of the ventral pallium (similarly to the caudal nidopallium and arcopallium) based on its expression of Lhx2/Lhx9 (it is called the caudal dorsolateral pallium or DLP by Abellán et al. [2009]). In frontal sections, the CDL/DLP ventricular zone starts to be visible caudal to the mesopallium, thus being adjacent to that of the nidopallium. The caudal part of the DVR in chickens also contains abundant Emx1-expressing cells (which concentrate in parts of the caudal nidopallium and arcopallium), and based on this the caudal DVR was initially thought to include a lateral pallial part [Puelles et al., 2000]. One possible explanation for the abundance of Emx1-expressing cells in the caudal aspect of the sauropsidian DVR is that these cells immigrate from the lateral pallium or dorsal pallium (although no experimental evidence exists yet for this). As noted above, the ventral pallial amygdala and adjacent areas of mammals also receive abundant Emx1 lineage cells from the lateral and/or dorsal pallium [Gorski et al., 2002; Remedios et al., 2007], and this also occurs in the ventral pallial amygdala of Xenopus [Brox et al., 2004]. Another possibility is that the caudal aspect of the ventral pallium (including the caudal DVR in sauropsids) is partially different. This is not so strange if we considered that the very rostral pole of the ventral pallium (including the olfactory bulb) is also special and different from the central parts (including the nidopallium), showing abundant expression of Emx1, Lhx2, and Lhx9 in postmitotic cells, but not Dachsund-2 [Puelles et al., 2000; Abellán et al., 2009; Sandoval, 2011]. This resembles the situation in the caudal DVR (and in the CDL/DLP). On the other hand, the olfactory superficial area of the lateral pallium, which typically reaches the superficial cortical area of the lateral pallial amyg- 


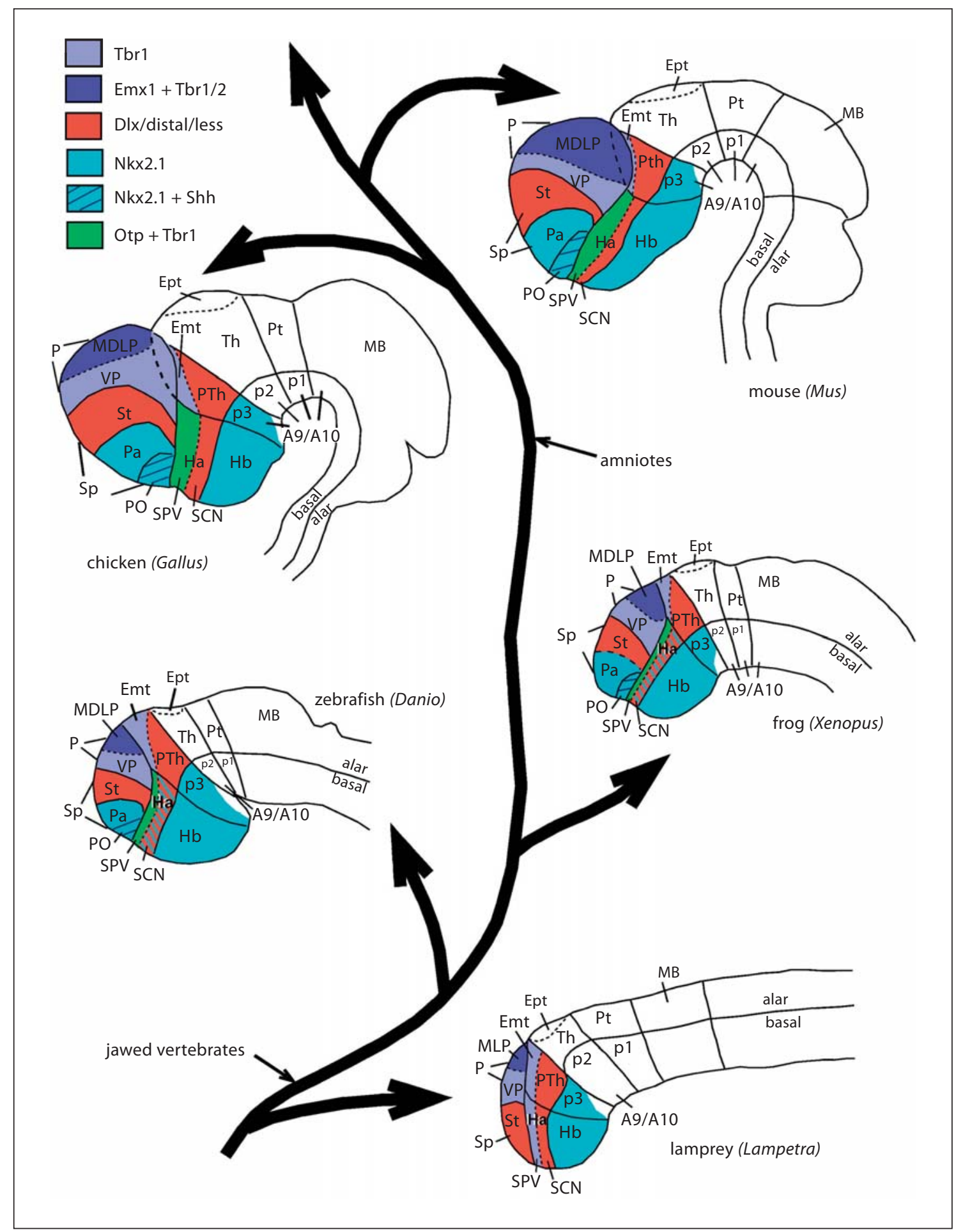

Fig. 5. Phylogenetic diagram representing some of the divisions and subdivisions of the embryonic forebrain (lateral view) in representative species of different vertebrates: a jawless fish (the lamprey), a teleost fish (the zebrafish), an amphibian (the anuran Xenopus), a sauropsid (the chicken), and a mammal (the mouse). Some of the developmental regulatory genes that characterize each division are shown. Note that Dlx/Distal-less is expressed in the whole subpallium (including striatal, pallidal, and preoptic subdivisions) in all vertebrates but for simplicity is only shown in the striatal subdivision. Also note the changes in the embryonic expression of Nkx2.1 during evolution, which may be related to evolutionary changes in the forebrain, also involving the amygdala. See text for more details. For abbreviations see list. 
dala in mammals, appears to be missing in birds [Reiner and Karten, 1985; Striedter et al., 1998; discussed by Abellán et al., 2009]. However, this appears to be a derived condition in birds in which the olfactory system is greatly reduced (with the vomeronasal component absent) compared to the ancestral condition in tetrapods [Reiner and Karten, 1985].

Subpallial Amygdala in Sauropsids and Amphibians

Similarly to that of mammals, the subpallium in sauropsids and amphibians studied thus far is characterized by expression of Mash-related and Dlx/Distal-less regulatory genes, but lacks Emx1 and Tbr1/Tbr2 expression, and this correlates well with its high density of GABAergic neurons (fig. 3-5) [Ferreiro et al., 1993; Jasoni et al., 1994; Fernandez et al., 1998; Puelles et al., 2000; Bachy et al., 2002; Brox et al., 2003; Wullimann and Mueller, 2004; Moreno and González, 2007b; Abellán and Medina, 2009; Moreno et al., 2009; Osorio et al., 2010]. Based on gene expression patterns, 3 major subdivisions, i.e. striatal, pallidal, and preoptic, are also present in the sauropsidian and amphibian subpallium during development [Fernandez et al., 1998; Puelles et al., 2000; Bachy et al., 2002; González et al., 2002a, b; Brox et al., 2003; van den Akker et al., 2008; Abellán and Medina, 2009; Moreno et al., 2009, 2010]. These striatal, pallidal, and preoptic subdivisions of sauropsids and amphibians are comparable, respectively, to the LGE, MGE, and preoptic subdivisions described in the subpallium of mammals, and are characterized by the same basic combinatorial codes of transcription factors that are found in mammals; moreover, as explained next, they also produce cell groups comparable to their counterparts in the centromedial amygdala of mammals (fig. 3-5).

Striatal Amygdala. The striatal subdivision shows ventricular expression of Pax6 and Dlx/Distal-less, but not Emx1 or Nkx2.1, and expresses Pax6 and Islet1 in the subventricular zone and/or mantle (fig. 3-5) [Fernandez et al., 1998; Puelles et al., 2000; Bachy et al., 2002; González et al., 2002a, b; Brox et al., 2003, 2004; Moreno et al., 2008a, b; 2009, 2010; Abellán and Medina, 2009]. Similarly to the mouse, in chickens and turtles there is a dorsal striatal subdomain that appears to be involved in producing Pax6 postmitotic neurons, including a neuron subset that reaches the amygdala (fig. 3, 4) [Puelles et al., 2000; Abellán and Medina, 2009]. However, in the anuran Xenopus, the dorsal part of the striatal division does not show ventricular expression of Pax6 and does not seem to produce Pax6 cells for the amygdala (fig. 3) [Moreno et al., 2008b, 2010]. The ventral striatal subdivi- sion is characterized by subventricular/mantle expression of Islet1 in all tetrapods studied (fig. 3, 4) [Stenman et al., 2003; Flames et al., 2007; Moreno et al., 2008a; Abellán and Medina, 2009], and at least in mouse and Xenopus this ventral striatal sector produces cells for the central amygdala [Moreno et al., 2008a; Waclaw et al., 2010; Bupesh et al., 2011b]. Using these general criteria, combined with previous neurochemical and hodological data, the striatal part of the amygdala (sometimes referred to as the 'central amygdala' or 'central extended amygdala') has been identified in amphibians [Moreno et al., 2008a, 2009] and sauropsids [Puelles et al., 2000; Abellán and Medina, 2009; Moreno et al., 2010] (fig. 3, 4). Therefore, it seems that the cellular composition of the identified 'central amygdala' is a little different in different tetrapods since it includes Pax6-expressing cells (derived from the dorsal striatal subdomain) in mice and sauropsids, but not amphibians, and Islet1-expressing cells (from the ventral striatal subdivision) in mice and amphibians, but data in sauropsids are unclear [Puelles et al., 2000; Moreno et al., 2008a, b, 2010; Abellán and Medina, 2009; Waclaw et al., 2010; Bupesh et al., 2011b]. Similarly to that of mammals, the striatal amygdala in sauropsids and amphibians receives gustatory/visceral input from the parabrachial and solitary nuclei of the brainstem, projects to hypothalamic and brainstem centers involved in control of ingestion and autonomic nervous system, and appears related to fear/anxiety and escape behaviors [reviewed by Moreno and González, 2006; Martínez-García et al., 2007].

Pallidal and Preoptic Amygdala. In sauropsids and amphibians, the pallidal subdivision is characterized by ventricular and/or subventricular expression of Dlx/Distal-less, Nkx2.1, Lhx6, and/or Lhx7/8 transcription factors and the absence of Pax6 and Shh at the ventricular zone level [Fernandez et al., 1998; Puelles et al., 2000; Bachy et al., 2002; Abellán and Medina, 2009; Moreno et al., 2010], while the preoptic subdivision expresses Dlx/ Distal-less, Nkx2.1, Lhx6, Lhx7/8, Islet1, and Shh in the ventricular and/or subventricular zone [Moreno et al., 2008a, 2010; Abellán and Medina, 2009; Dominguez et al., 2010] (fig. 3-5). The only exception is Lhx6 in amphibians since no published data have been found. As noted above, based on these criteria many neurons of the medial amygdala of mammals were proposed to originate either in the pallidal subdivision or the preoptic subdivision [García-López et al., 2008], which was later shown by fate mapping analysis [Hirata et al., 2009; Waclaw et al., 2010; Carney et al., 2010; Bupesh et al., 2011a]. The use of these criteria has also helped to support the identification 
of a 'medial amygdala' in sauropsids [Abellán and Medina, 2009; Moreno et al., 2010] and amphibians [Moreno et al., 2008a] (fig. 3, 4), the homology of which was previously proposed based on neurochemical, hodological, and some functional data [Reiner et al., 2004; Yamamoto et al., 2005; reviews by Moreno and González, 2006; Martínez-García et al., 2007]. The 'medial amygdala' identified in different species receives olfactory input and projects to hypothalamic centers involved in reproduction and agonistic behavior [review by Martínez-García et al., 2007]. Interestingly, based on the expression of $\mathrm{Nkx} 2.1$, Lhx6, and Shh, it has been proposed that the 'medial amygdala' of birds includes a mixture of pallidal and preoptic neurons and may be comparable to the anterior medial amygdala of mammals, where both types of cells are intermingled [Abellán and Medina, 2009]. Moreover, this avian nucleus, previously called the nucleus taenia of the amygdala, is rather small and does not receive vomeronasal input since this system has undergone regression in birds [Rei-ner et al., 2004; Yamamoto et al., 2005]. On the other hand, the 'medial amygdala' of amphibians contains Nkx2.1-expressing pallidal derived neurons [Moreno et al., 2008a] but appears to lack Shh-expressing preoptic neurons [Dominguez et al., 2010]. Moreover, the density of Nkx2.1 cells or other subpallial marker genes in the Xenopus 'medial amygdala' is low or moderate [Brox et al., 2004; Moreno et al., 2008a], suggesting the presence of cellular components from different embryonic sources, such as pallial and hypothalamic, as is true for the medial amygdala in mice, chickens, and turtles [Bardet et al., 2008; García-López et al., 2008; Abellán et al., 2009, 2010; Abellán and Medina, 2009; Moreno et al., 2010; Bupesh et al., 2011a]. In fact, some data suggest the presence of cells showing pallial marker gene expression (Lhx9 [Moreno et al., 2004; Brox et al., 2004]) or hypothalamic SPV gene expression (Otp [Bardet et al., 2008]) in the 'medial amygdala' of anurans. This will be discussed in more detail in the following sections.

Is There a Hypothalamic Contribution to the

Amygdala in Sauropsids and Amphibians?

As noted above, the medial amygdala of mammals contains an important subpopulation of neurons that originate in the SPV domain of the alar hypothalamus, and these neurons are characterized by expression of the transcription factors Otp and Lhx5 [Bardet et al., 2008; Abellán et al., 2010; García-Moreno et al., 2010; Bupesh et al., 2011a]. The SPV domain, showing the same molecular attributes, appears to contribute neurons to the 'medial amygdala' or 'medial extended amygdala' in chickens, turtles, and anurans (fig. 3, 4) [Bardet et al., 2008; Moreno et al., 2010]. In the mouse and the turtle, the SPV-derived neuron subpopulation that expresses Otp penetrates the caudal telencephalic vesicle and intermingles with subpallial neurons of the medial amygdala. However, in the chicken and the anuran Rana perezi, the SPV-derived subpopulation appears to reach only very caudal aspects of the telencephalon [Bardet et al., 2008], and it is not clear whether it overlaps all mediolateral parts of the subpallial 'medial extended amygdala' or only the medial BST (which also receives SPV-derived neurons in the mouse [Abellán et al., 2010; García-Moreno et al., 2010; Bupesh et al., 2011a]). The medial BST, but not the 'medial amygdala', of chickens and Xenopus contains vasotocin-immunoreactive cells [González and Smeets, 1992; Jurkevich et al., 1999] which as in mammals may have an SPV origin. Similarly to those of mammals, vasotocin cells of avian medial BST are sex steroid responsive and show sexual dimorphism that appears to be related to differences in the sexual behavior of males and females [Jurkevich et al., 1999; Panzica et al., 2001, 2002]. This appears to be similar in amphibians as well [Boyd, 1997]. Based on correlation with glutamate marker genes, it appears that SPV-derived cells that invade the medial extended amygdala in mammals and nonmammals are glutamatergic [Abellán et al., 2010].

Some Conclusions on the Development and

Evolution of the Amygdalar Mosaic in Tetrapods

Based on data obtained in a few representative species of mammals, sauropsids (including birds and reptiles), and amphibians, the amygdala in tetrapods is a mosaiclike structure that includes at least pallial, subpallial, and hypothalamic components, and these are characterized by the same basic combinations of developmental regulatory genes. However, the following differences are observed:

(1) In mammals, the pallial part of the amygdala (basal complex and cortical areas) includes lateral pallial and ventral pallial subdivisions, but only the ventral pallial component (mostly characterized by expression of both Lhx2 and Lhx9) may be present in sauropsids and amphibians (fig. 3; as explained above, the ventral pallial amygdala also appears to include a subpopulation of Emx1 lineage neurons in all tetrapods studied). The ventral pallial amygdala is quite large and elaborated in sauropsids, particularly in birds, which is in line with the general enlargement of the ventral pallium in this radiation [refer to Medina and Abellán, 2009, for a discussion on possible developmental mechanisms behind the ex- 
pansion of the ventral pallium in sauropsids]. The enlargement and complexity of this general territory in birds (including the nidopallium and arcopallium) has been correlated with the acquisition of more sophisticated behavioral repertoires, including a sophisticated control of vocalization used in several social contexts such as territoriality and courtship [reviewed in Jarvis et al., 2005; Martínez-García et al., 2007]. In mammals, sauropsids, and amphibians, the ventral pallium also produces a subset of glutamatergic neurons for the medial amygdala, the specific connections and function of which are unknown. In this context, it is interesting to note that in mammals glutamatergic projections from the medial amygdala primarily target hypothalamic centers involved in agonistic behavior (fight/defense) [Choi et al., 2005]. However, glutamatergic neurons of the medial amygdala originate in either the ventral pallium or the hypothalamus (see below).

(2) In mammals, the striatal part of the amygdala (central and intercalated amygdalar nuclei and dorsal anterior amygdala) includes at least two components, one expressing Pax6 that derives from the dorsal striatal subdivision and another one expressing Islet 1 that derives from the ventral striatal subdomain. While the ventral component may be present in all tetrapods (although more data are needed), the dorsal component is present in mammals and sauropsids but not amphibians. The Islet1-positive component of the striatal amygdala, which is present in amphibians, mice, and possibly sauropsids, appears to account for the typical connections and inferred function of the central amygdala, i.e. control of ingestion and relation to fear/anxiety and escape responses [Moreno and González, 2006]. However, the connections and function of the Pax6-expressing neurons are unknown, and this is important for understanding the meaning of this gain in evolution.

(3) In mammals, the pallidal part of the amygdala is characterized by expression of Nkx2.1 and Lhx6 and is involved in odor-guided reproductive behavior [Choi et al., 2005]. This pallidal subdivision appears to be present in all tetrapods studied, but its size is quite small in some sauropsids (such as the chicken). This may be a derived evolutionary condition in sauropsids with regression of the olfactory system, but we need to study other sauropsidian species with a highly developed olfactory system (e.g. lizards).

(4) In mammals, the preoptic part of the amygdala is characterized by expression of Shh and derives from Dbx1 preoptic progenitors. This part appears to be present in sauropsids, but a preoptic contribution to the amygdala in amphibians has been questioned [Dominguez et al., 2010]. Data in mammals indicate that preoptic neurons of the amygdala are GABAergic, and many of them are nitrergic [Hirata et al., 2009]. Nitrergic neurons are also present in the medial amygdala in anurans $[\mathrm{Mu}-$ ñoz et al., 1996], and perhaps the question requires further evaluation using other genetic markers or fate mapping. However, the specific connections and function of this cellular component are unknown, and the consequence of their putative gain in evolution unclear.

(5) In mammals, the hypothalamic SPV-derived part of the amygdala is characterized by expression of both Otp and Lhx5 (fig. 3). Based on the correlation of Otp with vasopressin/oxytocin [Wang and Lufkin, 2000], the SPV-derived cells of the medial amygdala may include steroid-responsive neurons involved in sexually dimorphic aspects of social behavior, such as parental care or aggressive behavior. The SPV forebrain subdivision is present and appears to contribute cells to the amygdala in all tetrapods studied. However, the SPV contribution appears to be larger in mammals than in nonmammalian tetrapods (at least in the species studied). This may be at least partially related to the larger size of the SPV in mammals compared to other vertebrates. It appears that the embryonic size of the SPV domain increases in the absence of $\mathrm{Nkx} 2.1$ expression as a consequence of the severe reduction of the basal hypothalamus [Marin et al., 2002]. In relation to this, it is interesting to note that the expression of Nkx2.1 in the hypothalamus is more extensive in the anuran Xenopus than in the mouse and chicken, and the situation in Xenopus is likely similar to that in the last common ancestor of tetrapods (see blue striped area in the alar hypothalamus in Xenopus in fig. 5 [van den Akker et al., 2008]). It also appears that Nkx2.1 hypothalamic expression has undergone a reduction from the ancestral condition in tetrapods to the avian and especially the mammalian radiation (fig. 5), and this may have had as a consequence an enlargement of the SPV in mammals and birds [Medina, 2008a; van den Akker et al., 2008].

\section{Did the First Vertebrates Possess an Amygdala and,} if So, How Was It?

The telencephalon, with pallial and subpallial divisions, has been described in the secondary prosencephalon in representative species of all vertebrates, including jawed and jawless fishes (fig. 5) [Wilson and Rubenstein, 2000; Murakami et al., 2001; reviews by Medina, 2008a; Medina and Abellán, 2009; Moreno et al., 2009]. In all vertebrates, the telencephalon is specified by the transcription factor Foxg1 (previously known as BF1). Also, 
in all vertebrates the pallium is characterized by expression of Emx1, Pax6, and Ngn2, while the subpallium is characterized by expression of Dlx/Distal-less [Puelles et al., 2000; Murakami et al., 2001; Wullimann and Mueller, 2004; Medina, 2008a; Medina and Abellán, 2009; Moreno et al., 2009]. Moreover, the pallium of fishes includes a ventral pallial subdivision highly related to the olfactory input, and this was likely present in the first vertebrates. It is therefore possible that a caudal aspect of the olfactory ventral pallium of the first vertebrates gave rise to the ventral pallial amygdala, although it is unclear when this occurred and what triggered it. A putative ventral pallial amygdala has been identified in teleost fishes based on behavioral approaches [Portavella et al., 2004a, b; Portavella and Vargas, 2005] (identified in the medial part of the everted pallium of goldfish, the topological position of which resembles that of the tetrapod ventral pallium [Nieuwenhuys et al., 1998]; similarly to the ventral pallial amygdala of mammals, this pallial area of goldfish is involved in avoidance and emotional learning), and it appears to be present in lungfishes as well [González and Northcutt, 2009]. However, the subpallium in jawless fishes is completely striatal-like since it does not show any Nkx2.1- or Shh-expressing domain. The latter domain is first observed in teleost fishes, suggesting that the first vertebrates lacked a pallido-preoptic subpallial domain and this evolved with the first jawed fishes [Murakami et al., 2001; Medina et al., 2005; Osorio et al., 2005; Medina, 2008b; van den Akker et al., 2008]. Thus, if the subpallial amygdala had been present in the first vertebrates, it would have only included a striatal component, and at least part of it may have been related to control of ingestion and fear/escape behaviors, as in other vertebrates. In teleost fishes, gustatory pathways are well developed and reach the telencephalic pallium and subpallium [Folgueira et al., 2003], including areas that are now considered to be part of the ventral pallium and striatum based on genetic markers [Mueller and Wullimann, 2009]. Therefore, these areas of teleost fishes receiving gustatory input resemble in this respect the ventral pallial and striatal amygdala of tetrapods. In agreement with this, these pallial and subpallial targets project to the hypothalamus and brainstem, including centers involved in ingestion control [Folgueira et al., 2004a, b]. Note that our claim does not exclude the possibility that part of the teleost ventral pallium or the striatum relate to other functional systems, such as the basal ganglia, as claimed by some authors [Medina, 2008b; Mueller et al., 2008]. Similarly to the situation in extant teleost fishes, it is possible that the telencephalon of the first jawed vertebrates may have included an amygdalar rudiment with ventral pallial and striatal components involved in ingestion control. It is also likely that these first jawed fishes already contained a pallido-preoptic domain, but it is unknown whether cells produced by this novel domain were already recruited for the medial amygdala. Nevertheless, the presence of a medial amygdala related to the vomeronasal system has recently been proposed in lungfishes [González and Northcutt, 2009]. However, this medial amygdala of lungfishes has been correlated to an area rich in Otp-expressing cells, which in tetrapods derives from the SPV. Perhaps, the SPV component was the initial part of the medial extended amygdala (perhaps including initially part of the BST), and later in evolution the pallidal and preoptic cells were incorporated into the whole medial extended amygdalar complex. Based on Otp expression, the SPV domain also appears to be present in teleost fishes [Eaton and Glasgow, 2007; Eaton et al., 2008], but it is unknown whether it exists in jawless fishes.

\section{Concluding Remarks: Major Steps in Amygdalar Development and Evolution}

The amygdala is involved in functions and behaviors that are critical for survival, including control of the neuroendocrine system and homeostasis, reproduction and fear/escape behaviors, and emotional learning. It is likely that this important center was present in the origin of vertebrates and may have included 3 basic components: (a) 2 components related to chemosensory information located in the telencephalon, i.e. one pallial (ventral pallial) component mainly related to olfaction and one subpallial (striatal) component apparently receiving ascending gustatory inputs (these pallial and subpallial telencephalic components receiving olfactory and possibly gustatory information may have been important for ingestion, fear/ escape, and perhaps other aspects of social behavior) and (b) 1 steroid hormone-regulated component derived from the hypothalamic SPV and characterized by the transcription factor Otp (this SPV-derived component was likely important for the control of the hypothalamo-hypophyseal and neuroendocrine system, which plays a crucial role in homeostasis control and many aspects of social behavior). At least these 3 basic components are present in lungfishes and tetrapods, and apparently in teleost fishes, and they were likely present in the forebrain of the first jawed vertebrates if not before. The evolution of the first jawed vertebrates has been correlated with the appearance of a novel embryonic domain in the subpallium, the pallido-preoptic domain, characterized by expression of 
Nkx2.1, which surely involved the production of new cell types in the telencephalon (this appears to be correlated with the evolutionary origin of the pallidum and possibly with new interneurons that migrated tangentially to the striatum and pallium [Medina, 2008b]). Eventually, some of those new neurons produced in the novel domain may have been recruited to be part of the amygdala, increasing the complexity of the amygdala and the repertoires of behaviors it controlled. It is unclear when this happened, but it seems clear that early tetrapods already had this characteristic since it is present in all extant tetrapods studied. During the evolution of tetrapods, the 4 major events that are worth noting are: (1) enlargement of the ventral pallium and thereby the ventral pallial amygdala in amniotes, particularly in sauropsids; (2) enlargement of the SPV domain in birds and especially mammals and an increase in its cellular contribution to the amygdala (par- ticularly in mammals); (3) appearance of novel cellular components of the subpallial amygdala in amniotes (Pax6 cells from dorsal striatum, perhaps a distinct preoptic contribution), and (4) appearance of a novel cellular component of the pallial amygdala in mammals (from the lateral pallium). These gradual increases in complexity during evolution, with changes in every radiation, need to be further examined in order to understand how they contributed to improving amygdalar control of emotions and social behavior.

\section{Acknowledgements}

This study was supported by a grant to L.M. from the Spanish Ministry of Science and Innovation, and FEDER (DGICYTFEDER grant No. BFU2009-07212/BFI; Acciones Integradas Hispano-Alemanas grant No. HD2008-0069).

\section{References}

-Abellán A, Legaz I, Vernier B, Rétaux S, Medina L (2009): Olfactory and amygdalar structures of the chicken ventral pallium based on the combinatorial expression patterns of LIM and other developmental regulatory genes. J Comp Neurol 20:166-186.

-Abellán A, Medina L (2008): Expression of cLhx6 and cLhx7/8 suggests a pallido-pedunculo-preoptic origin for the lateral and medial parts of the avian bed nucleus of the stria terminalis. Brain Res Bull 75:299-304.

-Abellán A, Medina L (2009): Subdivisions and derivatives of the chicken subpallium based on expression of LIM and other regulatory genes and markers of neuron subpopulations during development. J Comp Neurol 515: 465-501.

-Abellán A, Vernier B, Rétaux S, Medina L (2010): Similarities and differences in the forebrain expression of Lhx 1 and Lhx 5 between chicken and mouse: insights for understanding telencephalic development and evolution. J Comp Neurol 518:3512-3528.

- Alheid GF, Heimer L (1988): New perspectives in basal forebrain organization of special relevance for neuropsychiatric disorders: the striatopallidal, amygdaloid, and corticopetal components of substantia innominata. Neuroscience 27:1-39.

-Anderson S, Mione M, Yun K, Rubenstein JLR (1999): Differential origins of neocortical projection and local circuit neurons: role of Dlx genes in neocortical interneuronogenesis. Cereb Cortex 9:646-654.

Bachy I, Berthon J, Rétaux S (2002): Defining pallial and subpallial divisions in the developing Xenopus forebrain. Mech Dev 117: 163-172.

Amygdalar Evolution and Development
Bachy I, Vernier P, Retaux S (2001): The LIMhomeodomain gene family in the developing Xenopus brain: conservation and divergences with the mouse related to the evolution of the forebrain. J Neurosci 21:7620-7629.

- Bardet SM, Martinez-de-la-Torre M, Northcutt RG, Rubenstein JL, Puelles L (2008): Conserved pattern of OTP-positive cells in the paraventricular nucleus and other hypothalamic sites of tetrapods. Brain Res Bull 75: 231-235.

Berdel B, Moryś J (2000): Expression of calbindin-D28k and parvalbumin during development of rat's basolateral amygdaloid complex. Int J Dev Neurosci 18:501-513.

Boyd SK (1997): Brain vasotocin pathways and the control of sexual behaviors in the bullfrog. Brain Res Bull 44:345-350.

Brox A, Puelles L, Ferreiro B, Medina L (2003): Expression of the genes GAD67 and Distalless- 4 in the forebrain of Xenopus laevis confirms a common pattern in tetrapods. J Comp Neurol 461:370-393.

Brox A, Puelles L, Ferreiro B, Medina L (2004): Expression of the genes Emxl, Tbrl, and Eomes (Tbr2) in the telencephalon of Xenopus laevis confirms the existence of a ventral pallial division in all tetrapods. J Comp Neurol 474:562-577.

Bulfone A, Martinez S, Marigo V, Campanella M, Basile A, Quaderi N, Gattuso C, Rubenstein JL, Ballabio A (1999): Expression pattern of the Tbr2 (Eomesodermin) gene during mouse and chick brain development. Mech Dev 84:133-138.

Bupesh M, Legaz I, Abellán A, Medina L (2011a): Multiple telencephalic and extratelencephalic embryonic domains contribute neurons to the medial extended amygdala. J Comp Neurol 519:1505-1525.
Bupesh M, Abellán A, Medina L (2011b): Genetic and experimental evidence support the continuum of the central extended amygdala and a mutiple embryonic origin of its principal neurons. J Comp Neurol, in press; doi: 10.1002/cne.22719.

Butler AB (1994a): The evolution of the dorsal pallium in the telencephalon of amniotes: cladistic analysis and a new hypothesis. Brain Res Brain Res Rev 19:66-101.

Butler AB (1994b): The evolution of the dorsal thalamus of jawed vertebrates, including mammals: cladistic analysis and a new hypothesis. Brain Res Brain Res Rev 19:29-65.

- Butler AB, Reiner A, Karten HJ (2011): Evolution of the amniote pallium and the origins of mammalian neocortex. Ann NY Acad Sci 1225:14-27.

- Carney RS, Mangin JM, Hayes L, Mansfield K, Sousa VH, Fishell G, Machold RP, Ahn S, Gallo V, Corbin JG (2010): Sonic hedgehog expressing and responding cells generate neuronal diversity in the medial amygdala. Neural Dev 5:14-30.

Carroll SB, Grenier JK, Weatherbee SD (2001): From DNA to Diversity. Molecular Genetics and the Evolution of Animal Design, Blackwell Science, Massachusetts.

Charvet CJ, Striedter GF (2009a): Developmental origins of mosaic brain evolution: Morphometric analysis of the developing zebra finch brain. J Comp Neurol 514:203-213.

Charvet CJ, Striedter GF (2009b): Developmental basis for telencephalon expansion in waterfowl: enlargement prior to neurogenesis. Proc Biol Sci 276:3421-3427. 
Choi GB, Dong HW, Murphy AJ, Valenzuela DM, Yancopoulos GD, Swanson LW, Anderson DJ (2005): Lhx6 delineates a pathway mediating innate reproductive behaviors from the amygdala to the hypothalamus. Neuron 46:647-660.

Cobos I, Broccoli V, Rubenstein JLR (2005a): The vertebrate ortholog of Aristaless is regulated by Dlx genes in the developing forebrain. J Comp Neurol 483:292-303.

-Cobos I, Calcagnotto ME, Vilaythong AJ, Thwin MT, Noebels JL, Baraban SC, Rubenstein JLR (2005b): Mice lacking Dlx1 show subtype-specific loss of interneurons, reduced inhibition and epilepsy. Nat Neurosci 8: 1059-1068.

-Cobos I, Shimamura K, Rubenstein JL, Martínez S, Puelles L (2001): Fate map of the avian anterior forebrain at the four-somite stage, based on the analysis of quail-chick chimeras. Dev Biol 239:46-67.

-Cushing BS, Kramer KM (2005): Mechanisms underlying epigenetic effects of early social experience: the role of neuropeptides and steroids. Neurosci Biobehav Rev 29:10891105.

de Vries GJ, Miller MA (1998): Anatomy and function of extrahypothalamic vasopressin systems in the brain. Prog Brain Res 119:320.

-Domínguez L, Gonzalez A, Moreno N (2010): Sonic hedgehog expression during Xenopus laevis forebrain development. Brain Res 1347:19-32.

Eaton JL, Glasgow E (2007): Zebrafish orthopedia (otp) is required for isotocin cell development. Dev Genes Evol 217:149-158.

Eaton JL, Holmqvist B, Glasgow E (2008): Ontogeny of vasotocin-expressing cells in zebrafish: selective requirement for the transcriptional regulators orthopedia and singleminded 1 in the preoptic area. Dev Dyn 237: 995-1005.

- Fernandez AS, Pieau C, Repérant J, Boncinelli E, Wassef M (1998): Expression of the Emx-1 and Dlx-1 homeobox genes define three molecularly distinct domains in the telencephalon of mouse, chick, turtle and frog embryos: implications for the evolution of telencephalic subdivisions in amniotes. Development 125:2099-2111.

-Ferran JL, de Oliveira ED, Merchán P, Sandoval JE, Sánchez-Arrones L, Martínez-de-laTorre M, Puelles L (2009): Genoarchitectonic profile of developing nuclear groups in the chicken pretectum. J Comp Neurol 517:405451.

-Ferran JL, Sánchez-Arrones L, Sandoval JE, Puelles L (2007): A model of early molecular regionalization in the chicken embryonic pretectum. J Comp Neurol 505:379-403.

-Ferreiro B, Skoglund P, Bailey A, Dorsky R, Harris WA (1993): XASH1, a Xenopus homolog of achaete-scute: a proneural gene in anterior regions of the vertebrate CNS. Mech Dev 40: 25-36.
-Flames N, Pla R, Gelman DM, Rubenstein JL, Puelles L, Marín O (2007): Delineation of multiple subpallial progenitor domains by the combinatorial expression of transcriptional codes. J Neurosci 27:9682-9695.

Folgueira M, Anadón R, Yáñez J (2003): Experimental study of the connections of the gustatory system in the rainbow trout, Oncorhynchus mykiss. J Comp Neurol 2003;465:604619.

Folgueira M, Anadón R, Yáñez J (2004a): An experimental study of the connections of the telencephalon in the rainbow trout $(\mathrm{On}$ corhynchus mykiss). 1. Olfactory bulb and ventral area. J Comp Neurol 480:180-203.

-Folgueira M, Anadón R, Yáñez J (2004b): Experimental study of the connections of the telencephalon in the rainbow trout (Oncorhynchus mykiss). 2. Dorsal area and preoptic region. J Comp Neurol 480:204-233.

-Fowler M, Medina L, Reiner A (1999): Immunohistochemical localization of NMDA- and AMPA-type glutamate receptor subunits in the basal ganglia of red-eared turtles. Brain Behav Evol 54:276-289.

-García-López M, Abellán A, Legaz I, Rubenstein JL, Puelles L, Medina L (2008): Histogenetic compartments of the mouse centromedial and extended amygdala based on gene expression patterns during development. J Comp Neurol 506:46-74.

Garcia-Lopez R, Vieira C, Echevarria D, Martinez S (2004): Fate map of the diencephalon and the zona limitans at the 10-somites stage in chick embryos. Dev Biol 268:514-530.

García-Moreno F, Pedraza M, Di Giovannantonio LG, Di Salvio M, López-Mascaraque L, Simeone A, De Carlos JA (2010): A neuronal migratory pathway crossing from diencephalon to telencephalon populates amygdala nuclei. Nat Neurosci 13:680-689.

-González A, López JM, Marín O (2002a): Expression pattern of the homeobox protein NKX2-1 in the developing Xenopus forebrain. Brain Res Gene Expr Patterns 1:181185.

González A, López JM, Sanchez-Camacho C, Marín O (2002b): Regional expression of the homeobox gene NKX2-1 defines pallidal and interneuronal populations in the basal ganglia of amphibians. Neuroscience 114: 567-575.

-González A, Northcutt RG (2009): An immunohistochemical approach to lungfish telencephalic organization. Brain Behav Evol 74 $43-55$.

González A, Smeets WJ (1992): Distribution of vasotocin- and mesotocin-like immunoreactivities in the brain of the South African clawed frog Xenopus laevis. J Chem Neuroanat 5:465-479.

Gorski JA, Talley T, Qiu M, Puelles L, Rubenstein JLR, Jones KR (2002): Cortical excitatory neurons and glia, but not GABAergic neurons, are produced in the Emx1-expressing lineage. J Neurosci 22:6309-6314.
-Hevner RF, Shi L, Justice N, Hsueh Y, Sheng M, Smiga S, Bulfone A, Goffinet AM, Campagnoni AT, Rubenstein JLR (2001): Tbrl regulates differentiation of the preplate and layer 6. Neuron 29:353-366.

- Hirata T, Li P, Lanuza GM, Cocas LA, Huntsman MM, Corbin JG (2009): Identification of distinct telencephalic progenitor pools for neuronal diversity in the amygdala. Nat Neurosci 12:141-149.

Holmgren N (1925): Points of view concerning forebrain morphology in higher vertebrates. Acta Zool 6:413-477.

-Jarvis ED, Güntürkün O, Bruce L, Csillag A, Karten H, Kuenzel W, Medina L, Paxinos G, Perkel DJ, Shimizu T, Striedter G, Wild JM, Ball GF, Dugas-Ford J, Durand SE, Hough GE, Husband S, Kubikova L, Lee DW, Mello CV, Powers A, Siang C, Smulders TV, Wada K, White SA, Yamamoto K, Yu J, Reiner A, Butler AB, Avian Brain Nomenclature Consortium (2005): Avian brains and a new understanding of vertebrate brain evolution. Nat Rev Neurosci 6:151-159.

- Jasoni CL, Walker MB, Morris MD, Reh TA (1994): A chicken achaete-scute homolog (CASH-1) is expressed in a temporally and spatially discrete manner in the developing nervous system. Development 120:769-783.

Jurkevich A, Barth SW, Kuenzel WJ, Kohler A, Grossmann R (1999): Development of sexually dimorphic vasotocinergic system in the bed nucleus of stria terminalis in chickens. J Comp Neurol 408:46-60.

Kaas JH, Bullock TH (2007): Evolution of Nervous Systems: A Comprehensive Reference. Amsterdam, Academic Press-Elsevier, vol 2.

Kaoru T, Liu FC, Ishida M, Oishi T, Hayashi M, Kitagawa M, Shimoda K, Takahashi $\mathrm{H}$ (2010): Molecular characterization of the intercalated cell masses of the amygdala: implications for the relationship with the striatum. Neuroscience 166:220-230.

Karten HJ (1997): Evolutionary developmental biology meets the brain: the origins of mammalian neocortex. Proc Natl Acad Sci USA 94:2800-2804.

Kemppainen S, Pitkänen A (2000): Distribution of parvalbumin, calretinin, and calbindin$\mathrm{D}(28 \mathrm{k})$ immunoreactivity in the rat amygdaloid complex and colocalization with gamma-aminobutyric acid. J Comp Neurol 426: 441-467.

Lagutin OV, et al. (2003): Six3 repression of Wnt signaling in the anterior neuroectoderm is essential for vertebrate forebrain development. Genes Dev 17:368-379.

Legaz I (2006): Caracterización genética y origen de las neuronas de la región claustroamigdalina en ratón; doctoral thesis, University of Murcia, Murcia.

Legaz I, Olmos L, Real MA, Guirado S, Dávila JC, Medina L (2005): Development of neurons and fibers containing calcium binding proteins in the pallial amygdala of mouse, with special emphasis on those of the basolateral amygdalar complex. J Comp Neurol 488:492-513. 
-Long JE, Swan C, Liang WS, Cobos I, Potter GB, Rubenstein JLR (2009): Dlx1\&2 and Mash1 transcription factors control striatal patterning and differentiation through parallel and overlapping pathways. J Comp Neurol 512: 556-572.

Lupo G, Harris WA, Lewis KE (2006): Mechanisms of ventral patterning in the vertebrate nervous system. Nat Rev Neurosci 7:103114.

-Marín O, Baker J, Puelles L, Rubenstein JLR (2002): Patterning of the basal telencephalon and hypothalamus is essential for guidance of cortical projections. Development 129: 761-773.

-Martínez-de-la-Torre M, Pombal MA, Puelles L (2011): Distal-less-like protein distribution in the larval lamprey forebrain. Neuroscience 178:270-284.

Martínez-García F, Novejarque A, Lanuza E (2007): Evolution of the amygdala in vertebrates; in Kaas J, Bullock TH (eds): Evolution of Nervous Systems: A Comprehensive Reference. Amsterdam, Academic Press-Elsevier, vol 2, pp 255-334.

McDonald AJ (1996): Glutamate and aspartate immunoreactive neurons of the rat basolateral amygdala: colocalization of excitatory amino acids and projections to the limbic circuit. J Comp Neurol 365:367-379.

McDonald AJ, Mascagni F (2001): Colocalization of calcium-binding proteins and GABA in neurons of the rat basolateral amygdala. Neuroscience 105:681-693.

Medina L (2007a): Field homologies; in Kaas JH, Striedter GF, Rubenstein JL (eds): Evolution of Nervous Systems: A Comprehensive Reference. Amsterdam, Academic Press-Elsevier, vol 1, pp 73-87.

Medina L (2007b): Do birds and reptiles possess homologues of mammalian visual, somatosensory and motor cortices? in Kaas JH, Bullock TH (eds): Evolution of Nervous Systems: A Comprehensive Reference. Amsterdam, Academic Press-Elsevier, vol 2, pp 163-194.

Medina L (2008a): Evolution and embryological development of forebrain; in Binder MD, Hirokawa N, Windhorst U (eds): Encyclopedia of Neuroscience. Berlin, Springer, pp 11721192.

Medina L (2008b): Basal ganglia: evolution; in Squie LR (ed): Encyclopedia of Neuroscience. Amsterdam, Elsevier, pp 67-85.

Medina L, Abellán A (2009): Development and evolution of the pallium. Semin Cell Dev Biol 20:698-711.

- Medina L, Brox A, Legaz I, García-López M, Puelles L (2005): Expression patterns of developmental regulatory genes show comparable divisions in the telencephalon of Xenopus and mouse: insights into the evolution of the forebrain. Brain Res Bull 66:297-302.

Medina L, Legaz I, González G, de Castro F, Rubenstein JL, Puelles L (2004): Expression of Dbx1, Neurogenin 2, Semaphorin 5A, Cadherin 8, and Emxl distinguish ventral and lateral pallial histogenetic divisions in the developing claustroamygdaloid complex. J Comp Neurol 474:504-523.
Medina L, Reiner A (2000): Do birds possess homologues of mammalian primary visual, somatosensory and motor cortices? Trends Neurosci 23:1-12.

Michaud JL, Rosenquist T, May NR, Fan CM (1998): Development of neuroendocrine lineages requires the bHLH-PAS transcription factor SIM1. Genes Dev 12:3264-3275.

- Moreno N, Bachy I, Rétaux S, González A (2004): LIM-homeodomain genes as developmental and adult genetic markers of Xenopus forebrain functional subdivisions. J Comp Neurol 472:52-72.

Moreno N, Domínguez L, Rétaux S, González A (2008a): Islet1 as a marker of subdivisions and cell types in the developing forebrain of Xenopus. Neuroscience 154:1423-1439.

Moreno N, González A (2006): The common organization of the amygdaloid complex in tetrapods: new concepts based on developmental, hodological and neurochemical data in anuran amphibians. Prog Neurobiol 78:6190.

Moreno N, González A (2007a): Development of the vomeronasal amygdala in anuran amphibians: hodological, neurochemical, and gene expression characterization. J Comp Neurol 503:815-831.

Moreno N, González A (2007b): Regionalization of the telencephalon in urodele amphibians and its bearing on the identification of the amygdaloid complex. Front Neuroanat 1:112.

-Moreno N, González A, Rétaux S (2009): Development and evolution of the subpallium. Semin Cell Dev Biol 20:735-743.

-Moreno N, Morona R, López JM, González A (2010): Subdivisions of the turtle Pseudemys scripta subpallium based on the expression of regulatory genes and neuronal markers. J Comp Neurol 518:4877-4902.

Moreno N, Rétaux S, González A (2008b): Spatio-temporal expression of Pax6 in Xenopus forebrain. Brain Res 1239:92-99.

Mueller T, Vernier P, Wullimann MF (2006): A phylotypic stage in vertebrate brain development: GABA cell patterns in zebrafish compared with mouse. J Comp Neurol 494:620634.

Mueller T, Wullimann MF (2009): An evolutionary interpretation of teleostean forebrain anatomy. Brain Behav Evol 74:30-42.

Mueller T, Wullimann MF, Guo S (2008): Early teleostean basal ganglia development visualized by zebrafish Dlx2a, Lhx6, Lhx7, Tbr2 (eomesa), and GAD67 gene expression. J Comp Neurol 507:1245-1257.

Muller JF, Mascagni F, McDonald AJ (2003): Synaptic connections of distinct interneuronal subpopulations in the rat basolateral amygdalar nucleus. J Comp Neurol 456:217-236.

- Muñoz M, Muñoz A, Marín O, Alonso JR, Arévalo R, Porteros A, González A (1996): Topographical distribution of NADPH-diaphorase activity in the central nervous system of the frog, Rana perezi. J Comp Neurol 367:54-69.
Murakami Y, Ogasawara M, Sugahara F, Hirano S, Satoh N, Kuratani S (2001): Identification and expression of the lamprey Pax6 gene: evolutionary origin of the segmented brain of vertebrates. Development 128:3521-3531.

Nieuwenhuys R, ten Donkelaar HJ, Nicholson C (1998): The Central Nervous System of Vertebrates. Berlin, Springer.

Osório J, Mazan S, Rétaux S (2005): Organisation of the lamprey (Lampetra fluviatilis) embryonic brain: insights from LIM-homeodomain, Pax and hedgehog genes. Dev Biol 288:100-112.

Osório J, Mueller T, Rétaux S, Vernier P, Wullimann MF (2010): Phylotypic expression of the bHLH genes Neurogenin2, Neurod, and Mash1 in the mouse embryonic forebrain. J Comp Neurol 518:851-871.

- Panzica GC, Aste N, Castagna C, Viglietti-Panzica C, Balthazart J (2001): Steroid-induced plasticity in the sexually dimorphic vasotocinergic innervation of the avian brain: behavioral implications. Brain Res Brain Res Rev 37:178-200.

- Panzica GC, Bakthazart J, Pessatti M, VigliettiPanzica C (2002): The parvocellular vasotocin system of Japanese quail: a developmental and adult model for the study of influences of gonadal hormones on sexually differentiated and behaviorally relevant neural circuits. Environ Health Perspect 110(suppl 3):423-428.

-Paré D, Quirk GJ, LeDoux JE (2004): New vistas on amygdala networks in conditioned fear. J Neurophysiol 92:1-9.

- Pombal MA, Megías M, Bardet SM, Puelles L (2009): New and old thoughts on the segmental organization of the forebrain in lampreys. Brain Behav Evol 74:7-19.

Pombero A, Martinez S (2009): Telencephalic morphogenesis during the process of neurulation: an experimental study using quailchick chimeras. J Comp Neurol 512:784-797.

Portavella M, Torres B, Salas C (2004b): Avoidance response in goldfish: emotional and temporal involvement of medial and lateral telencephalic pallium. J Neurosci 24:2335-2342.

- Portavella M, Torres B, Salas C, Papini MR (2004a): Lesions of the medial pallium, but not of the lateral pallium, disrupt spaced-trial avoidance learning in goldfish (Carassius auratus). Neurosci Lett 362:75-78

-Portavella M, Vargas JP (2005): Emotional and spatial learning in goldfish is dependent on different telencephalic pallial systems. Eur J Neurosci 21:2800-2806.

Puelles L (2001a): Brain segmentation and forebrain development in amniotes. Brain Res Bull 55:695-710

Puelles L (2001b): Thoughts on the development, structure and evolution of the mammalian and avian telencephalic pallium. Philos Trans R Soc Lond B Biol Sci 356:1583-1598.

Puelles L (2011): Pallio-pallial tangential migrations and growth signalling: new scenario for cortical evolution? Brain Behav Evol, Epub ahead of print. 
-Puelles L, Amat JA, Martinez-de-la-Torre M (1987): Segment-related, mosaic neurogenetic pattern in the forebrain and mesencephalon of early chick embryos. 1. Topography of AChE-positive neuroblasts up to stage HH18. J Comp Neurol 8:247-268.

- Puelles L, Kuwana E, Puelles E, Bulfone A, Shimamura K, Keleher J, Smiga S, Rubenstein JL (2000): Pallial and subpallial derivatives in the embryonic chick and mouse telencephalon, traced by the expression of the genes Dlx-2, Emx-1, Nkx-2.1, Pax-6, and Tbr-1. J Comp Neurol 424:409-438.

Puelles L, Martínez S, Martínez-de-la-Torre M, Rubenstein JL (2004): Gene maps and related histogenetic domains in the forebrain and midbrain; in Paxinos G (ed): The Rat Nervous System, ed 3. Amsterdam, Elsevier-Academic Press, pp 3-25.

Puelles L, Martinez de-la-Torre M, Paxinos G, Watson C, Martinez S (2007): The Chick Brain in Stereotaxic Coordinates. New York, Academic Press.

Puelles L, Medina L (2002): Field homology as a way to reconcile genetic and developmental variability with adult homology. Brain Res Bull 57:243-255.

Puelles L, Rubenstein JL (1993): Expression patterns of homeobox and other putative regulatory genes in the embryonic mouse forebrain suggest a neuromeric organization. Trends Neurosci 16:472-479.

- Puelles L, Rubenstein JL (2003): Forebrain gene expression domains and the evolving prosomeric model. Trends Neurosci 26:469-476.

- Reiner A, Karten HJ (1985): Comparison of olfactory bulb projections in pigeons and turtles. Brain Behav Evol 27:11-27.

- Reiner A, Perkel DJ, Bruce LL, Butler AB, Csillag A, Kuenzel W, Medina L, Paxinos G, Shimizu T, Striedter G, Wild M, Ball GF, Durand S, Güntürkün O, Lee DW, Mello CV, Powers A, White SA, Hough G, Kubikova L, Smulders TV, Wada K, Dugas-Ford J, Husband S, Yamamoto K, Yu J, Siang C, Jarvis ED, Avian Brain Nomenclature Forum (2004): Revised nomenclature for avian telencephalon and some related brainstem nuclei. J Comp Neurol 473:377-414.

Remedios R, Huilgol D, Saha B, Hari P, Bhatnagar L, Kowalczyk T, Hevner RF, Suda Y, Aizawa S, Ohshima T, Stoykova A, Tole S (2007): A stream of cells migrating from the caudal telencephalon reveals a link between the amygdala and neocortex. Nat Neurosci 10:1141-1150.

Remedios R, Subramanian L, Tole S (2004): LIM genes parcellate the embryonic amygdala and regulate its development. J Neurosci 24: 6986-6990.

-Rubenstein JL, Shimamura K, Martinez S, Puelles L (1998): Regionalization of the prosencephalic neural plate. Annu Rev Neurosci 21: 445-477.
Sánchez-Arrones L, Ferrán JL, Rodríguez-Gallardo L, Puelles L (2009): Incipient forebrain boundaries traced by differential gene expression and fate mapping in the chick neural plate. Dev Biol 335:43-65.

Sandoval JE (2011): Aportaciones a la organización estructural del telencéfalo de aves; $\mathrm{PhD}$. Dissertation, University of Murcia, Murcia.

Shimamura K, Hartigan DJ, Martinez S, Puelles L, Rubenstein JL (1995): Longitudinal organization of the anterior neural plate and neural tube. Development 121:3923-3933.

Shimamura K, Martinez S, Puelles L, Rubenstein JL (1997): Patterns of gene expression in the neural plate and neural tube subdivide the embryonic forebrain into transverse and longitudinal domains. Dev Neurosci 19:8896.

Shimamura K, Rubenstein JL (1997): Inductive interactions direct early regionalization of the mouse forebrain. Development 124: 2709-2718.

Smidt MP, Burbach JP (2007): How to make a mesodiencephalic dopaminergic neuron. Nat Rev Neurosci 8:21-32.

Soma M, Aizawa H, Ito Y, Maekawa M, Osumi N, Nakahira E, Okamoto H, Tanaka K, Yuasa S (2009): Development of the mouse amygdala as revealed by enhanced green fluorescent protein gene transfer by means of in utero electroporation. J Comp Neurol 513: 113-128.

-Stenman J, Toresson H, Campbell K (2003): Identification of two distinct progenitor populations in the lateral ganglionic eminence: implications for striatal and olfactory bulb neurogenesis. J Neurosci 23:167-174.

Stoykova A, Gruss P (1994): Roles of Pax-genes in developing and adult brain as suggested by expression patterns. J Neurosci 14:13951412.

Striedter GF (1997): The telencephalon of tetrapods in evolution. Brain Behav Evol 49:179213.

Striedter GF (2005): Principles of Brain Evolution. Sunderland, Sinauer Associates.

- Striedter GF, Charvet CJ (2008): Developmental origins of species differences in telencephalon and tectum size: morphometric comparisons between a parakeet (Melopsittacus undulatus) and a quail (Colinus virgianus). J Comp Neurol 507:1663-1675.

Striedter GF, Marchant TA, Beydler S (1998): The 'neostriatum' develops as part of the lateral pallium in birds. J Neurosci 18:5839-5849.

-Stühmer T, Anderson SA, Ekker M, Rubenstein JL (2002a): Ectopic expression of the Dlx genes induces glutamic acid decarboxylase and Dlx expression. Development 129:245252.

Stühmer T, Puelles L, Ekker M, Rubenstein JLR (2002b): Expression from a Dlx gene enhancer marks adult mouse cortical GABAergic neurons. Cereb Cortex 12:75-85.
- Sussel L, Marin O, Kimura S, Rubenstein JL (1999): Loss of Nkx2.1 homeobox gene function results in a ventral to dorsal molecular respecification within the basal telencephalon: evidence for a transformation of the pallidum into the striatum. Development 126: 3359-3370.

-Swanson LW (2000): Cerebral hemisphere regulation of motivated behavior. Brain Res 886 : 113-164.

-Swanson LW, Petrovich GD (1998): What is the amygdala? Trends Neurosci 21:323-331.

- Szele FG, Chin HK, Rowlson MA, Cepko CL (2002): Sox-9 and cDachsund-2 expression in the developing chick telencephalon. Mech Dev 112:179-182.

Teramitsu I, Kudo LC, London SE, Geschwind DH, White SA (2004): Parallel FoxP1 and FoxP2 expression in songbird and human brain predicts functional interaction. J Neurosci 24:3152-3163.

- Tole S, Remedios R, Saha B, Stoykova A (2005): Selective requirement of Pax6, but not Emx2, in the specification and development of several nuclei of the amygdaloid complex. J Neurosci 25:2753-2760.

van den Akker WM, Brox A, Puelles L, Durston AJ, Medina L (2008): Comparative functional analysis provides evidence for a crucial role for the homeobox gene Nkx2.1/Titf-1 in forebrain evolution. J Comp Neurol 506:211223.

-Waclaw RR, Ehrman LA, Pierani A, Campbell K (2010): Developmental origin of the neuronal subtypes that comprise the amygdalar fear circuit in the mouse. J Neurosci 30: 6944-6953.

Wang W, Lufkin T (2000): The murine Otp homeobox gene plays an essential role in the specification of neuronal cell lineages in the developing hypothalamus. Dev Biol 227:

432-449.
Wilson SW, Houart C (2004): Early steps in the development of the forebrain. Dev Cell 6: 167-181.

Wilson SW, Rubenstein JLR (2000): Induction and dorsoventral patterning of the telencephalon. Neuron 28:641-651.

-Wullimann MF, Mueller T (2004): Teleostean and mammalian forebrains contrasted: evidence from genes to behavior. J Comp Neurol 475:143-162.

-Wullimann MF, Rink E, Vernier P, Schlosser G (2005): Secondary neurogenesis in the brain of the African clawed frog, Xenopus laevis, as revealed by PCNA, Delta-1, Neurogenin-related-1, and NeuroD expression. J Comp Neurol 489:387-402.

Yamamoto K, Sun Z, Wang HB, Reiner A (2005): Subpallial amygdala and nucleus taeniae in birds resemble extended amygdala and medial amygdala in mammals in their expression of markers of regional identity. Brain Res Bull 66:341-347. 